NISTIR 6766

\title{
Powder-Matrix Systems for Safer Handling and Storage of Suppression Agents
}

Gregory T. Linteris

Harsha K. Chelliah

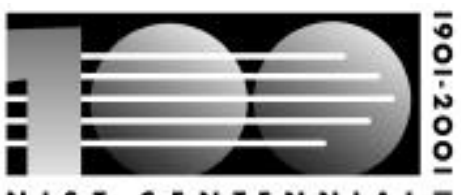

NIST CENTENNIAL

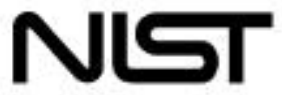

National Institute of Standards and Technology Technology Administration, U.S. Department of Commerce 


\section{Powder-Matrix Systems for Safer Handling and Storage of Suppression Agents
Agint}

Gregory T. Linteris

Building and Fire Research Laboratory National Institute of Standards and Technology

Harsha K. Chelliah Mechanical and Aerospace Engineering

University of Virginia

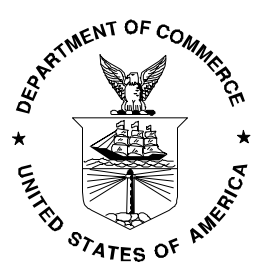

U.S. Department of Commerce Norman Y. Mineta, Secretary

Technology Administration Dr. Cheryl L. Shavers, Under Secretary of Commerce for Technology 


\title{
Final Technical Report
}

\section{Powder - Matrix Systems for Safer Handling and Storage of Suppression Agents}

\author{
$4 \mathrm{~A} / 1 / 8$ \\ Date: $1 / 31 / 2001$
}

Gregory T. Linteris

National Institute of Standards and Technology

Building and Fire Research Laboratory

Fire Science Division

100 Bureau Dr. Stop 8652

Gaithersburg MD 20899-8652
Harsha H. Chelliah

Mechanical and Aerospace Eng.

University of Virginia

122 Engineer's Way

P.O.Box 400746

Charlottesville, VA 22904-4746

July, 2001

Final Technical Report, March 1999 - December 2000

The views and conclusions contained in this document are those of the authors and should not be interpreted as representing the official policies, either expressed or implied, of the Strategic Environmental Research and Development Program, National Institute of Standards and

Technology, or any other part of the U.S. Government.

Sponsored by:

The Department of Defense

Strategic Environmental Research and Development Program 


\section{Table of Contents}

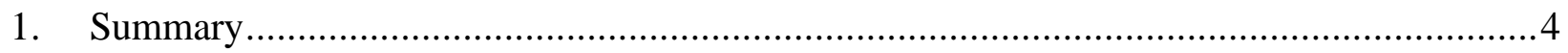

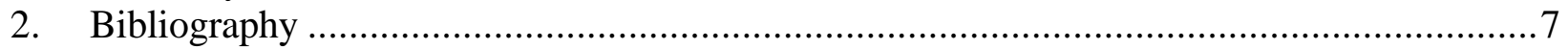

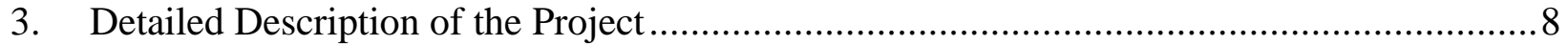

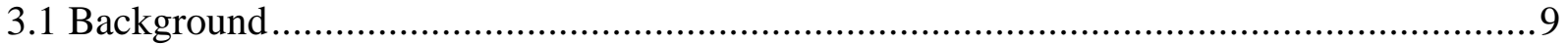

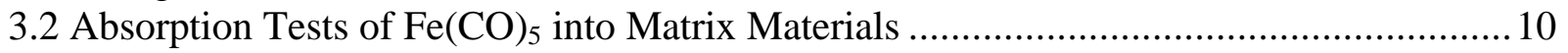

3.2.1. Matrix Materials and Super Agents Considered .................................................... 10

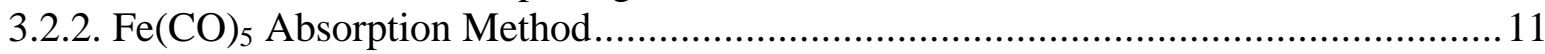

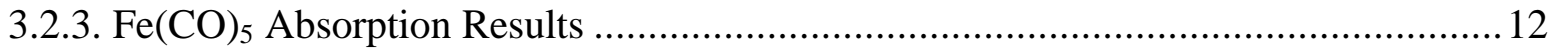

3.2.4. Quantification of $\mathrm{Fe}(\mathrm{CO})_{5}$ Absorption/Desorption ................................................ 14

3.2.5. Surrogate Agents for Absorption/Desorption Testing .............................................. 16

3.3 Methods of Quantifying Suppression Effects by Particulates .......................................... 17

3.3.1 Counterflow Diffusion Flames with Inert and $\mathrm{NaHCO}_{3}$ Particles ...............................18

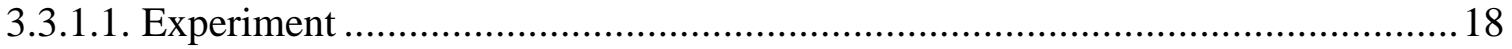

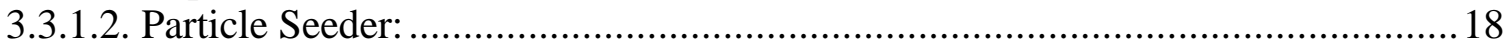

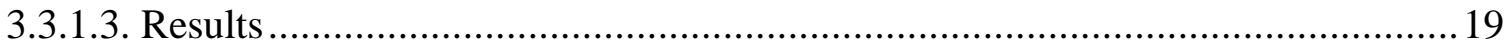

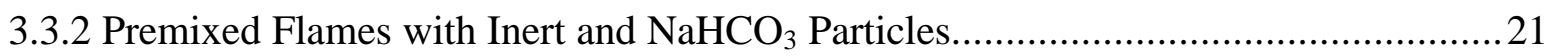

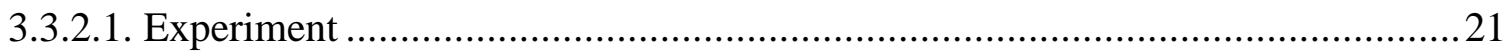

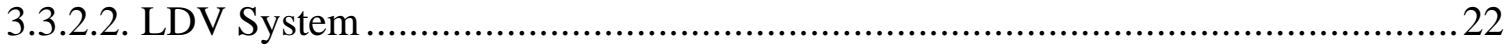

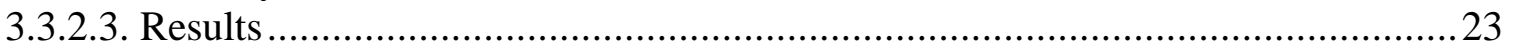

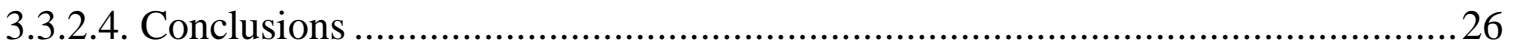

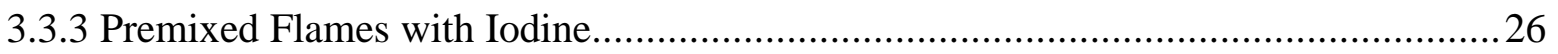

3.4. Complexation of Super-Effective Metals ...................................................................2

3.4.1. Super Agents and Complexing Ligands Considered.............................................2

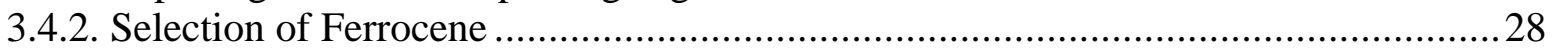

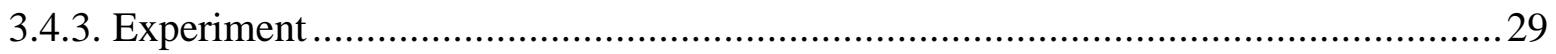

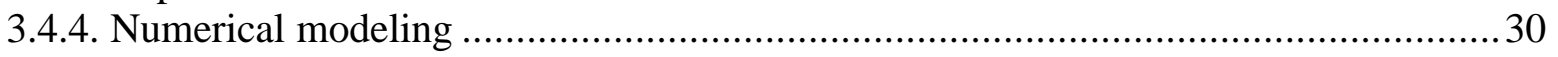

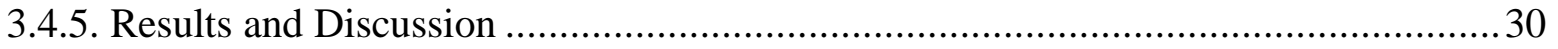

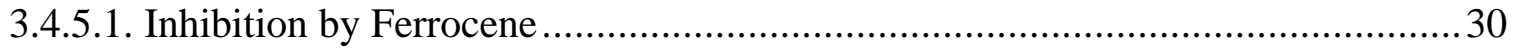

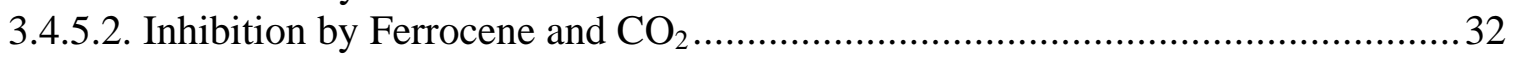

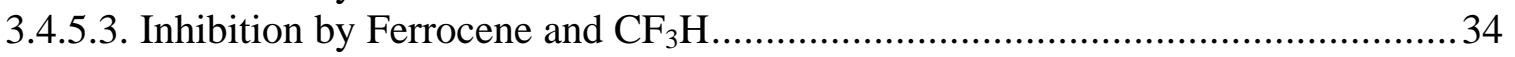

3.4.5.4. Comparison of Individual and Blended Performance.........................................36

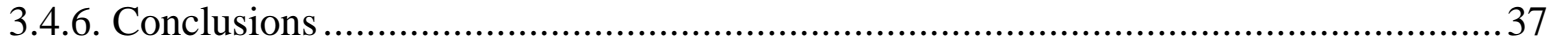

3.5. Cup Burner Flame Extinction Tests with Super-Effective Chemical Inhibitors ................ 37

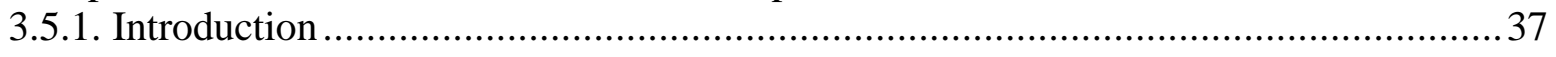

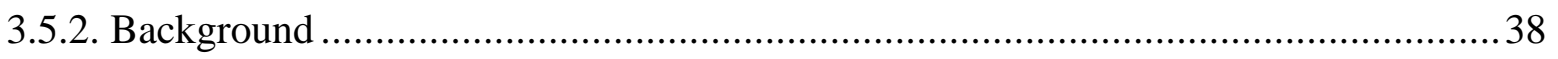

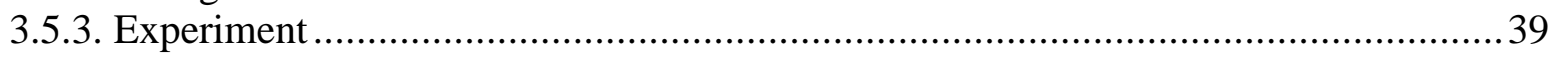

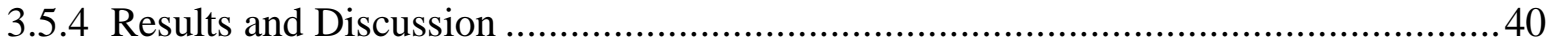

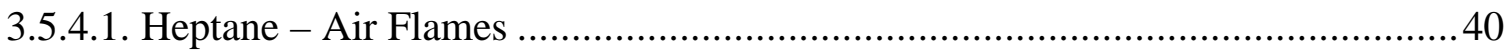

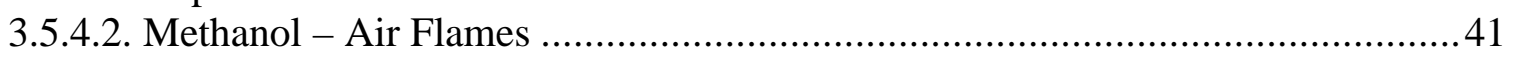

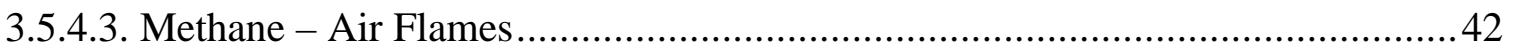

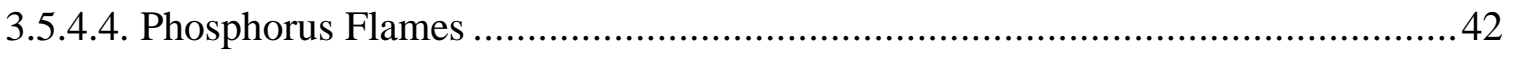

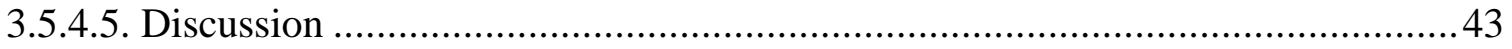

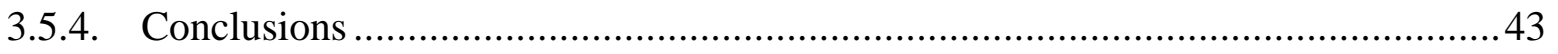




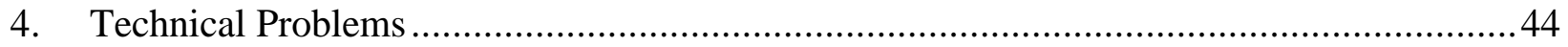

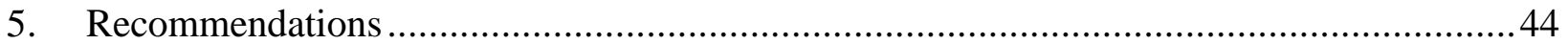

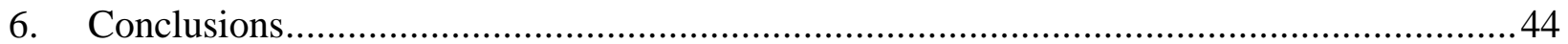

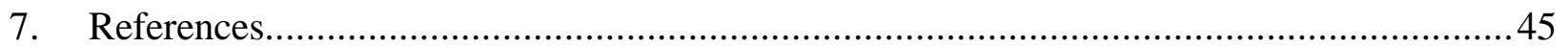




\section{Summary}

\subsection{Task Objectives}

To assess, and if reasonable develop, the capability for absorbing/adsorbing or complexing effective but toxic fire suppression agents in inorganic media. The encapsulated agent can then be safely delivered to the fire where the high temperatures will release the agent.

\subsection{Technical Problems}

There exist chemicals that are up to two orders of magnitude more effective than $\mathrm{CF}_{3} \mathrm{Br}$ at reducing the overall reaction rate of some flames. They tend, however, to be organometallic compounds that are highly toxic and flammable. If a means can be developed for absorbing them in inert carriers, their extraordinary effectiveness might be harnessed while rendering them safe to handle and use. Alternatively, there may exist stable compounds that contain the active chemical moiety which can be safely handled and yet will release the active chemical under the appropriate conditions. The challenge in this project was originally perceived to be to find agent/matrix combinations which were stable for storage, but also effective in releasing the active species into the flame region to suppress the fire. In conducting the research for the project, however, we discovered that the flame suppression behavior of previously postulated 'super-effective agents' depends quite strongly upon the type of flame in which the tests are conducted. Hence, the project took a somewhat changed route as we worked to determine the merits of the super agents for more practical flames.

\subsection{General Methodology}

As perceived, the project was a combination of various approaches. A literature survey would determine the complete range of possible 1.) super-effective agents, 2.) agent support matrices, and 3.) inorganic forms of complexing the active metal-based species. The most promising of these would be tested in the lab for agent uptake, stability, and release at elevated temperatures. Finally, the results of the laboratory tests would be used to guide flame tests of the most promising combinations. Early results showed, however, that there were quantitative flame inhibition data for only a handful of metal species $(\mathrm{Fe}, \mathrm{Cr}$, and $\mathrm{Pb}$ ). The latter two were not pursued because of the environmental toxicity of the element. Thus, the list of known super agents was quickly culled down those containing one element: iron. We felt that demonstration tests with $\mathrm{Fe}(\mathrm{CO})_{5}$ in various available support materials were achievable in the time available. The general methodology then, was one of laboratory tests of agent uptake, stability, and release, and laboratory flame tests of complexed or encapsulated agent effectiveness. As we progressed, we obtained dramatic results for the effectiveness of $\mathrm{Fe}(\mathrm{CO})_{5}$ which would change the interpretation of this as well as other NGP project results. 


\subsection{Technical Results}

The most important finding of this research is that the behavior of some super-agents relative to $\mathrm{CF}_{3} \mathrm{Br}$ is markedly different in cup-burner flames (which more closely resemble buoyant diffusion flame fires) than it is in either premixed or counterflow diffusion flames. In the past, the counterflow diffusion flame was believed to provide a good metric of inhibitor effectiveness. Our present work indicates, however, that the performance benefit of an agent may be dependent upon the type of flame used in the test. As a result of our tests of $\mathrm{Fe}(\mathrm{CO})_{5}$ in cup-burner flames, it does not appear that getting this agent into a flame in any form will provide much benefit (if any) over alkali metal compounds. Hence, work to absorb it or other super-effective agents may not be warranted. In addition, other projects that seek to evaluate or discover new, supereffective compounds may need to take these recent findings into consideration. Specific test results of this project are:

a.) Measured the flame speed of premixed methane-air flames in the presence of ferrocene $(\mathrm{Fec})$ and $\mathrm{Fe}(\mathrm{CO})_{5}$ at $\mathrm{T}_{\mathrm{in}}=80^{\circ} \mathrm{C}$, at $\phi=0.9,1.0$, and 1.1, and $X_{O_{2}, \mathrm{ox}}=0.2$, 0.21 , and 0.24 .

b.) Measured cup-burner extinction conditions of methane-air, heptane-air, and methanol-air flames in the presence of $\mathrm{CO}_{2}$ and $\mathrm{Fe}(\mathrm{CO})_{5}$ or $\mathrm{CF}_{3} \mathrm{Br}$.

c.) Measured the fuel consumption rate of liquid-fueled cup burners in the presence of suppressants $\mathrm{CO}_{2}, \mathrm{Fe}(\mathrm{CO})_{5}$, and $\mathrm{CF}_{3} \mathrm{Br}$.

d.) Measured the $\mathrm{Fe}(\mathrm{CO})_{5}$ absorption rate into zeolite-NaX, zeolite-NaY, silica gel, aerogel.

e.) Measured the $I_{2}$ absorption rate into crystalline silica and zeolite-NaX.

f.) Measured the effect of inert particles on the flame speed and extinction strain rate of methane-air flames.

\subsection{Important Findings and Conclusions}

a.) $\mathrm{An} \mathrm{Fe}(\mathrm{CO})_{5}$ mass fraction of $0.33,0.26,0.21$, and 0.14 to 2.0 can be absorbed into zeolite-NaX, zeolite-NaY, porous silica, and aerogel, respectively.

b.) An $\mathrm{I}_{2}$ mass fraction of 0.06 and 0.24 can be absorbed into crystalline silica and zeolite-NaX, respectively.

c.) $\mathrm{Fe}(\mathrm{CO})_{5}$ added to zeolite- $\mathrm{NaX}$ and zeolite-NaY is pyrophoric in air.

d.) $\mathrm{Fe}(\mathrm{CO})_{5}$ decomposes when added to zeolite- $\mathrm{NaX}$ (and probably Zeolite-NaY also).

e.) The powerful flame inhibition property of iron is not unique to $\mathrm{Fe}(\mathrm{CO})_{5}$, and there exists at least one other, much less toxic compound (ferrocene) which is equally as effective at reducing the burning velocity of premixed methane-air flames.

f.) Combining a highly effective chemical agent (e.g., Fec) with a thermally acting agent (e.g., $\mathrm{CO}_{2}$ ) can mitigate the loss of effectiveness of iron compounds in premixed methane air flames.

g.) Combining iron compounds with HFCs is not an effective combination because stable iron-halogen species act as sinks for active gas-phase iron compounds. 
h.) Inert particles of $\mathrm{SiO}_{2}$ or Zeolite-NaX added to premixed methane-air flames at mass fractions of about $1 \%$ reduce the flame speed by about $5 \%$.

i.) The performance of a super-effective inhibitor can vary drastically depending upon the type of flame in which it is tested.

\subsection{Significant Hardware Developments}

We designed, built, tested, and optimized the following:

a.) A system for absorbing $\mathrm{Fe}(\mathrm{CO})_{5}$ into porous particles

b.) A premixed flame burner for use with added particles.

c.) A counterflow diffusion flame burner for use with added particles.

d.) A steady and reliable particle seeding system for premixed or counterflow burners.

e.) A system for measuring the fuel consumption rate of liquid-fueled cup burner flames.

f.) A system for adding ferrocene to flames.

g.) A heated, insulated, premixed burner system which operates at elevated temperatures, and to which lower vapor pressure agents (such as ferrocene) can be added.

h.) A new experimental protocol for testing super-effective agents in the cup burner.

\subsection{Special Comments}

It is an unexpected result that the super-effective agent $\mathrm{Fe}(\mathrm{CO})_{5}$ does not appear to work well in the cup burner. Unless $\mathrm{Fe}(\mathrm{CO})_{5}$ (or any other super agent) itself works to suppress cup burner flames, it is very unlikely that any encapsulated or complexed form of these agents will work either. Since the reasons for this poor behavior are not clearly understood, we believe that it is of value to perform some limited additional tests to determine the reasons for the lack of effectiveness of this otherwise powerful agent. It is important to resolve this unexpected result, not only to understand the behavior of these most effective catalytic agents, but also to help direct efforts to define the most appropriate test burner for use as an agent screen in future research.

\subsection{Implications for Further Research}

The present results for $\mathrm{Fe}(\mathrm{CO})_{5}$ in cup burner flames, carried out at one or two $\mathrm{Fe}(\mathrm{CO})_{5}$ concentrations in the fuel or air stream, are intriguing. In order to understand this unexpected poor performance of the super agents in the cup burner, we recommend the following additional tests.

A first step is to perform the tests of the effectiveness of blends of $\mathrm{CO}_{2}$ and $\mathrm{Fe}(\mathrm{CO})_{5}$ in the cup burner over a range of mole fractions of $\mathrm{Fe}(\mathrm{CO})_{5}$. The purpose of these tests is to search for abrupt changes in the efficacy of $\mathrm{Fe}(\mathrm{CO})_{5}$ in reducing the amount of $\mathrm{CO}_{2}$ necessary to extinguish the cup burner flame. From our previous work in premixed and counterflow diffusion flames, we found distinctly different behavior of $\mathrm{Fe}(\mathrm{CO})_{5}$ at high and low mole fraction, which was attributed to condensation of iron compounds. If 
similar behavior was found in cup burners, it would lead us to suspect similar reasons for the change in effectiveness.

A next step to take to try to understand the unexpected poor performance of the super agent $\mathrm{Fe}(\mathrm{CO})_{5}$ would be to test super-effective agents other than those of iron in the cup burner. Other metallic agents may have different mechanisms of radical re-combination (involving different types of metal-compound intermediates, or different flame radicals). These other metals (and their oxides and hydroxides) will have different vapor pressures, thermodynamic equilibrium conditions, and particle formation characteristics as compared to iron, providing insight into the factors which are important for their effectiveness, or lack thereof. Since phosphorus compounds are leading candidates as super agents, it is essential to tests these compounds (alone and in combination with $\mathrm{CO}_{2}$ ) in the cup burner to see if they are effective for this type of flame.

It has been hypothesized that the cause of the poor performance of $\mathrm{Fe}(\mathrm{CO})_{5}$ in the cup burner flames is the formation of particles, which are then prevented from entering the flame region by flow field and thermophoretic effects. The most direct way to test this hypothesis is to measure for particles in the air stream of cup burner flames with added $\mathrm{Fe}(\mathrm{CO})_{5}$ using classical laser scattering and extinction techniques. Finally, experiments and numerical modeling of the flame structure of cup burner flames inhibited by inert and catalytic agents are recommended. Clearly, even with particle measurements in $\mathrm{Fe}(\mathrm{CO})_{5^{-}}$ inhibited cup-burner flames, and interpretation of the data based on similar measurements and modeling in premixed and counterflow diffusion flames, it will not be possible to truly understand the loss of effectiveness in the cup burner until flame extinction in the cup burner in general is understood. This could be achieved through comprehensive modeling and accompanying experiments on cup-burner flame structure. Given the extensive database of flame suppressant effectiveness in the cup burner, and its wide use, modeling and experiments to understand this ubiquitous metric seem warranted.

\section{Bibliography}

1. Babushok, V., Tsang, W., Linteris, G. T. and Reinelt, D., "Chemical Limits to Flame Inhibition," Combustion and Flame, 115, pp. 551-560, 1998.

2. Rumminger, M., Reinelt, D., Babushok, V., and Linteris, G. T., "Numerical Study of the Inhibition of Premixed and Diffusion Flames by Iron Pentacarbonyl," Combustion and Flame, 116(1-2), pp. 207-219, 1999.

3. Rumminger, M. D.; Reinelt, D.; Babushok, V. I.; Linteris, G. T., "Inhibition of Flames by Iron Pentacarbonyl," Halon Options Technical Working Conference. HOTWC-98. Proceedings. May 12-14, 1998, Albuquerque, New Mexico, 1-12 pp, 1998.

4. Rumminger, M.D. and Linteris, G.T., "Particle Measurements in $\mathrm{Fe}(\mathrm{CO})_{5}$-Inhibited Flames," NIST Annual Conference on Fire Research, Rockville MD, Nov. 2-5, 1998.

5. Rumminger, M.D. and Linteris, G.T., "The Role of Particles in Flame Inhibition by Iron Pentacarbonyl," to appear in the proceedings of the Halon Options Technical Working Conference, Albuquerque, NM, April 1999. 
6. Rumminger, M.D. and Linteris, G.T., "Particle Measurements in Flames Inhibited by Iron Pentacarbonyl", Joint Meeting of the United States Sections of the Combustion Institute, Washington, D.C., March 1999.

7. Linteris, G.T. and Rumminger, M.D., "Flame Inhibition by Ferrocene, Carbon Dioxide, and Trifluoromethane Blends: Synergistic and Anti-synergistic Effects," 1999 Fall Technical Meeting, Eastern States Section of the Combustion Institute, July, 1999.

8. Rumminger, M.D. and Linteris, G.T., "Numerical Modeling of Inhibition of Counterflow Diffusion Flames by Iron Pentacarbonyl", in Fire Safety Science Proceedings of the Sixth International Symposium, International Association for Fire Safety Science (Michel Curtat, Ed.), Marne-La-Vallee, France, 2000, pp. 289-300.

9. Rumminger, M.D. and Linteris, G.T., "Inhibition of Premixed Carbon Monoxide-HydrogenOxygen-Nitrogen Flames by Iron Pentacarbonyl," Combustion and Flame, 120(4):451-464, 2000.

10. Linteris, G.T. and Rumminger, M.D., "Premixed Carbon Monoxide/Nitrous Oxide/Hydrogen Flames: Measured and Calculated Burning Velocities with and without $\mathrm{Fe}(\mathrm{CO})_{5}$," Combustion and Flame, 122(1/2):58-75, 2000.

11. Rumminger, M.D. and Linteris, G.T. "The Role of Particles in Flame Inhibition by Iron Pentacarbonyl," Combustion and Flame, 123(1/2):82-94, 2000.

12. Linteris, G.T. and Rumminger, M.D., "Flame Inhibition by Ferrocene, Carbon Dioxide, and Trifluoromethane Blends: Synergistic and Anti-synergistic Effects," 1999 Fall Technical Meeting, Eastern States Section of the Combustion Institute, July, 1999.

13. Linteris, G.T. and Rumminger, M.D., "Flame Inhibition by Ferrocene, Alone and with $\mathrm{CO}_{2}$ and $\mathrm{CF}_{3} \mathrm{H}$," Halon Options Technical Working Conference, Albuquerque, NM, May 2-4, 2000, pp. 129-140.

14. Lazzarini, A. K., Krauss, R. H., Chelliah, H. K., and Linteris, G. T., "Extinction of Counterflow Diffusion Flames with Fine-Water Droplets," Halon Options Technical Working Conference, Albuquerque, NM, May 2-4, 2000, pp. 195-203.

15. Linteris, G.T. and Rumminger, M.D., "Flame Inhibition by Thermal and Catalytic Blends: Synergistic and Antagonistic Effects," accepted for publication in Proceedings of the Combustion Institute, Vol. 28, April 2000.

16. Lazzarini, A.M., Krauss, R.H., Chelliah, H.K., and Linteris, G.T, "Extinction Conditions of Non-premixed Flames with Fine Droplets of Water and Water-NaOH Solutions," accepted for publication in Proceedings of the Combustion Institute, Vol. 28, April 2000.

17. Wanigarathne, P.C., Krauss, R. H., Chelliah, H. K., and Davis, R.J., "Fire Suppression by Particulates Containing Metallic Compounds," Halon Options Technical Working Conference, Albuquerque, NM, May 2-4, 2000, pp. 393-402.

\section{Detailed Description of the Project}

The overall goal of the project is to determine if effective but flammable and/or toxic metalbased compounds can be made safer and easier to handle through either their absorption/adsorption into inert matrix materials, or through complexation of the active species in a larger molecule. To this end, we performed several separate tasks, as described below. The first sub-section below describes helpful background information on the action of the supereffective agents relevant to subsequent discussions. In the next sub-section, we describe the work to examine absorption/adsorption and desorption of the super agents into the inert matrix 
materials. Of course, the interaction of these matrix particles (containing the super-agent) with actual flames is an essential part of their performance. Consequently, we developed accurate methods of quantifying the flame inhibition/suppression performance of particles added to flames, and describe those methods in a separate sub-section. The other method for releasing effective super agents into the flame is to complex them into a larger molecule; that is, to build them into a less toxic and easier to handle molecule which then decomposes in the flame, releasing the active moiety. A sub-section below describes tests with iron complexed in a safer form. Finally, it is important to investigate the efficacy of the super agents in flames that closely resemble fires. The cup burner flame resembles buoyant diffusion flames. It is widely used in the fire protection community for evaluating the effectiveness of fire suppressants, and there is an extensive database on the cup-burner extinction values for fire suppressants. Consequently, we used the cup-burner as an indicator of the effectiveness of super agents in buoyant diffusion flame fires. The last sub-section describes those tests.

\subsection{Background}

It is well known that some metallic compounds reduce the burning velocity of premixed flames one or two orders of magnitude more than does $\mathrm{CF}_{3} \mathrm{Br}$. The overall reaction rate, which is related to the square of the burning velocity [1], is thus greatly reduced by these agents under premixed conditions. If means could be found to incorporate such agents in a practical fire suppressant (particularly for unoccupied spaces), very effective agents may be possible. Previous work has shown this superior performance for iron pentacarbonyl $\mathrm{Fe}(\mathrm{CO})_{5}$, tetraethyllead $\left(\mathrm{C}_{2} \mathrm{H}_{5}\right)_{4} \mathrm{~Pb}$, and chromyl chloride $\mathrm{CrO}_{2} \mathrm{Cl}_{2}$ [2]. One of these agents, $\mathrm{Fe}(\mathrm{CO})_{5}$, has been studied in some detail. It has been found to be an extraordinarily effective flame inhibitor, up to two orders of magnitude more efficient than $\mathrm{CF}_{3} \mathrm{Br}$ at reducing the burning velocity of premixed flames $[3,4]$.

Recent progress has been made in understanding $\mathrm{Fe}(\mathrm{CO})_{5}{ }^{6} \mathrm{~s}$ mechanism of inhibition [5-11]. Experiments and modeling have quantified its performance and explained its mechanism of inhibition for a variety of conditions. The strong inhibition is believed to occur from a catalytic radical recombination cycle involving iron oxides and hydroxides:

$$
\begin{gathered}
\mathrm{FeOH}+\mathrm{H} \leftrightarrow \mathrm{FeO}+\mathrm{H}_{2} \\
\mathrm{FeO}+\mathrm{H}_{2} \mathrm{O} \leftrightarrow \mathrm{Fe}(\mathrm{OH})_{2} \\
\frac{\mathrm{Fe}(\mathrm{OH})_{2}+\mathrm{H} \leftrightarrow \mathrm{FeOH}+\mathrm{H}_{2} \underline{\mathrm{O}}}{\text { (net: } \left.\mathrm{H}+\mathrm{H} \leftrightarrow \mathrm{H}_{2}\right) .}
\end{gathered}
$$

This mechanism leads to very strong inhibition for $\mathrm{Fe}(\mathrm{CO})_{5}$ mole fractions below about 100 $\mathrm{ppm}^{1}$; however, above this value, the inhibitor begins to lose its effectiveness. We believe this to occur from condensation of the active iron-containing intermediates to particles [7,9]. The reduction in the effectiveness of $\mathrm{Fe}(\mathrm{CO})_{5}$ as the mole fraction increases was shown to be much more dramatic in premixed flames than in counterflow diffusion flames. Any practical fire suppressant using these super-effective agents would require some method to overcome their loss of effectiveness and high toxicity.

${ }^{1}$ All references to ppm in the report are on a volume basis, and refer to $\mu \mathrm{L} / \mathrm{L}$. 
If some means can be found of absorbing/adsorbing $\mathrm{Fe}(\mathrm{CO})_{5}$ into an inert matrix and then releasing it in the flame zone, or, alternatively, if other non-toxic forms of iron exist which are also superb inhibitors and which maintain their action up to higher mole fractions, they could lead to the development of very effective fire suppressants.

Throughout this report, uncertainties are calculated from the individual uncertainty components and root mean square summation of components [12,13]. All uncertainties are reported as expanded uncertainties: $X \pm U$, where $U$ is $k u_{c}$, and is determined from a combined standard uncertainty (estimated standard deviation) $u_{c}$, and a coverage factor $k=2$ (level of confidence approximately $95 \%$ ). Likewise, when reported, the relative uncertainty is $U / X \cdot 100 \%$, or $k u_{c} /$ $X \cdot 100 \%$.

\subsection{Absorption Tests of $\mathrm{Fe}(\mathrm{CO})_{5}$ into Matrix Materials}

The primary objectives of this task were to develop a system for introducing the inhibitor into the matrix materials, quantify the absorption and desorption processes of the inhibitor into and out of the matrix, and investigate the thermal stability of the matrix-inhibitor combination. We first describe the possible matrix materials and super agents considered, and the rational for the tests cases adopted. Next, we describe the method of absorbing the agent into the matrix. Following that, we present the results for the amount of $\mathrm{Fe}(\mathrm{CO})_{5}$ which we were able to add to the various support materials. The next sub-section describes additional methods to study the details of the $\mathrm{Fe}(\mathrm{CO})_{5}$ absorption. Finally, we present data on tests with $\mathrm{I}_{2}$-impregnated particles which were used as a surrogate material to test the concept.

\subsubsection{Matrix Materials and Super Agents Considered}

The selection of matrix material must consider several key factors. Since the primary purpose of the matrix is storage and transport of the super agent, for ideal testing purposes it should be an inert compound. In this context, porous silica and aerogel fits these criteria well. In contrast, zeolite particles considered have $\mathrm{Na}^{+}$imbedded in the structure and can influence the flame inhibition. Similarly, porous carbon particles can promote flame propagation through oxidation of carbon. For this reason, porous carbon particles were excluded from the list of matrix materials.

Another important criterion is the surface area to mass of the particle. For example, zeolite particles have a high surface area to mass ratio of about $800 \mathrm{~m}^{2} / \mathrm{g}$, while crystalline sodium bicarbonate particles have a very low value. The porous silica particles considered had an intermediate value of $550 \mathrm{~m}^{2} / \mathrm{g}$. Aerogel particles have high pore volume to mass, but offer lower agent adsorption surface area.

Seeding of the matrix material in flame experiments is another important criterion to be considered. For example, submicron particles were hard to seed in a steady, consistent manner as opposed to particles above $5 \mu \mathrm{m}$. In this regard, zeolite particles with a mean diameter of 2 $\mu \mathrm{m}$ were on the borderline of our seeding capabilities. Hence, the maximum mass fraction of seeded zeolite particles did not exceed $0.6 \%$. In comparison, porous silica particles in the size 
range of $15 \mu \mathrm{m}$ to $40 \mu \mathrm{m}$ were well behaved in our seeder, and a mass fraction as high as $6 \%$ was attained in flame experiments.

Finally, the desorption rate of the agent from the pore structure must be favorable. Ideally, the matrix material must be stable during the heating and desorption process. Unfortunately, a sample of zeolite particles collected after passing through a premixed flame indicated spherical particles greater than the initial size. This perhaps indicates that the matrix material had melted and, through agglomeration, formed large spherical particles.

Because of the superior flame inhibition properties of $\mathrm{Fe}(\mathrm{CO})_{5}$, most of the absorption effort was devoted to this compound. As an alternative, iodine $\mathrm{I}_{2}$ was considered as a surrogate material for testing the performance of an absorbed agent. Previous studies had indicated a weak chemical adsorption of iodine in silica, premixed flame inhibition experiments with these iodine absorbed porous silica particles were performed.

\subsection{2. $\mathrm{Fe}(\mathrm{CO})_{5}$ Absorption Method}

The system developed for introducing the $\mathrm{Fe}(\mathrm{CO})_{5}$ into the various matrix materials is shown in Figure 1. The technique is a standard method for absorbing compounds into matrix materials. The apparatus can be evacuated by a vacuum pump to a pressure of $7 \mathrm{~Pa}$. In the initial absorption studies, about $1 \mathrm{~g}$ of solid support material is first inserted into one of the tubes. This sample is then heated under vacuum conditions to remove the absorbed gases from the internal pore structure, which typically takes about $3 \mathrm{~h}$ to $4 \mathrm{~h}$. After removal of the absorbed gases, the support material is allowed to return to room temperature. The $\mathrm{Fe}(\mathrm{CO})_{5}$ to be absorbed is then poured into the second tube, with the interconnecting valve closed. While keeping the $\mathrm{Fe}(\mathrm{CO})_{5}$ close to its freezing temperature, the valve in the interconnecting tube is opened briefly to remove the gas- $\mathrm{Fe}(\mathrm{CO})_{5}$ mixture. Finally, the valve to the suction pump is closed and the interconnecting valve is left open, allowing the $\mathrm{Fe}(\mathrm{CO})_{5}$ vapor to diffuse and absorb into the pore structure. This vapor-phase absorption process typically takes about 1 to 2 days.

Iron pentacarbonyl was absorbed into particles of zeolite-NaX, zeolite- $\mathrm{NaY}$, silica aerogel, and porous silica. An overview is presented below, followed by a description of more detailed tests for the quantity and characteristics of the absorbed iron compounds. 


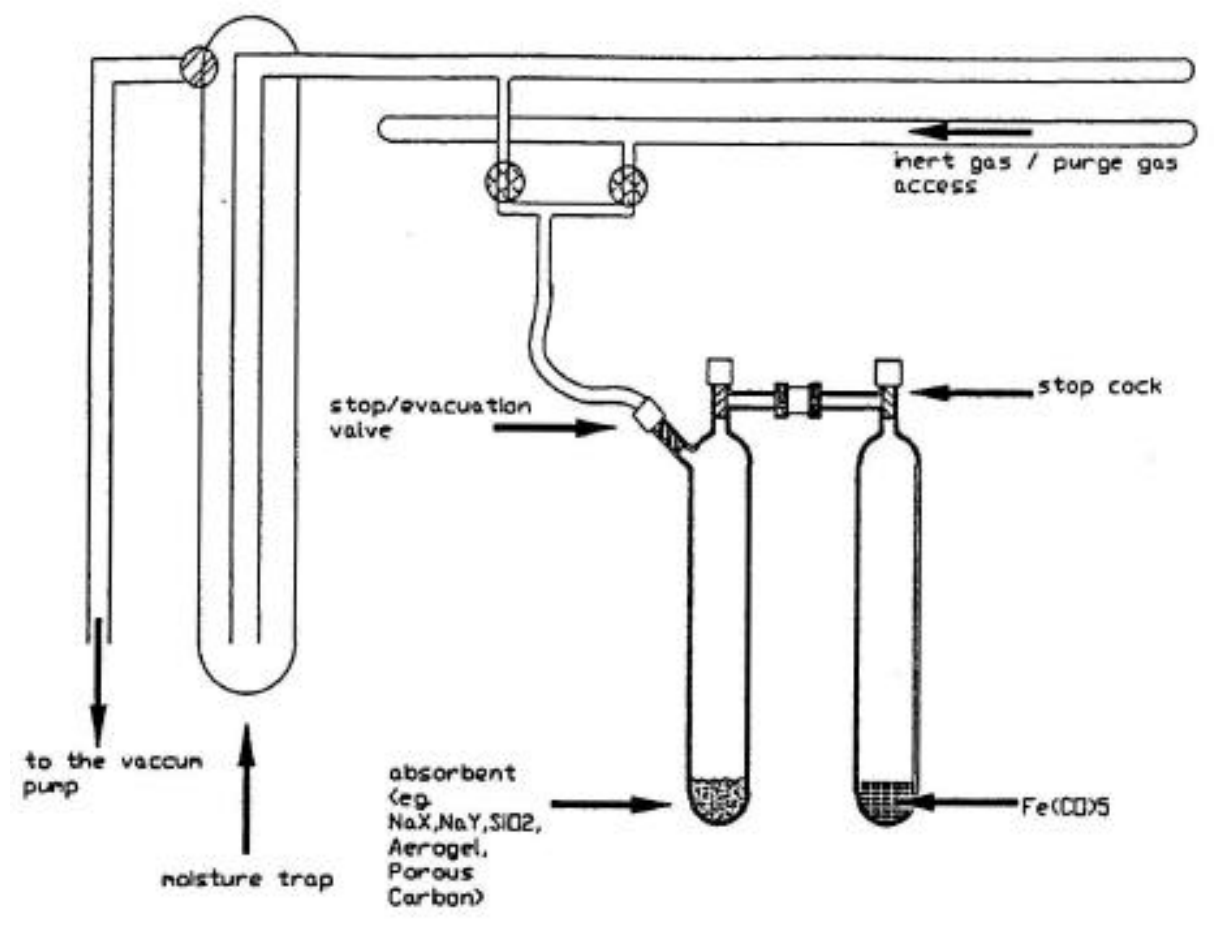

Figure 1 - Schematic of the experimental setup for $\mathrm{Fe}(\mathrm{CO})_{5}$ absorption.

\subsection{3. $\mathrm{Fe}(\mathrm{CO})_{5}$ Absorption Results}

For zeolite-NaX with pore volume of $0.3 \mathrm{~cm}^{3} / \mathrm{g}$ [14], the estimated mass of $\mathrm{Fe}(\mathrm{CO})_{5}$ required to completely saturate the internal pore volume is about $0.3 \mathrm{~g} / \mathrm{g}$ of zeolite-X. About $10 \%$ of additional $\mathrm{Fe}(\mathrm{CO})_{5}$ is generally poured into the glass tube to ensure complete absorption. Based on the mass increase of the tube containing zeolite-NaX, about $33 \%$ increase in gross mass of the particles was observed, which is consistent with the estimate based on the internal pore volume. This implies that the particles of zeolite- $\mathrm{NaX}$ absorb the $\mathrm{Fe}(\mathrm{CO})_{5}$ into their pore structure, as opposed to just adsorbing the agent onto the external surface. This amount of mass uptake is encouraging, since only $100 \mathrm{ppm}$ of $\mathrm{Fe}(\mathrm{CO})_{5}$ added to the reaction zone should reduce the overall reaction rate by a factor of four. Thus, adding a mass loading of particles of $1 \%$ should provide sufficient $\mathrm{Fe}(\mathrm{CO})_{5}$ to yield an observable burning velocity or extinction strain rate reduction in our apparatus.

After the $\mathrm{Fe}(\mathrm{CO})_{5}$ was absorbed into the zeolite-NaX, the particles changed color to a faint brown/yellow. Based on the color change, the absorption appeared to be uniform in the zeolite particle sample. In addition, a very faint coating (presumably $\mathrm{Fe}(\mathrm{CO})_{5}$ ) is observed on the tube walls. When the absorption process is allowed to take place with the chemical hood light on, the color of the $\mathrm{Fe}(\mathrm{CO})_{5}$-absorbed zeolite particles is a darker shade of brown. This is believed to be caused by the decomposition of $\mathrm{Fe}(\mathrm{CO})_{5}$ to $\mathrm{Fe}_{2}(\mathrm{CO})_{9}$ (iron nonacarbonyl) in the presence of light. 
When the $\mathrm{Fe}(\mathrm{CO})_{5}$-absorbed zeolite-NaX was exposed to air by opening the valve, a reaction front propagated rapidly across the sample, sometimes with a bright orange colored emission (apparently a flame inside the absorption tube). Hence, it appears that the iron pentacarbonyl reacted pyrophorically with air. Additional experiments were conducted by exposing the $\mathrm{Fe}(\mathrm{CO})_{5}$-impregnated zeolite-NaX particles to either pure oxygen or nitrogen. In oxygen, the particles showed even more violent reaction, whereas in nitrogen, there was no reaction. These tests show that the decomposition process is related to the oxygen concentration. While these observations are qualitative, this unexpected result indicates that zeolite-NaX may not be an appropriate support matrix for delivering unreacted $\mathrm{Fe}(\mathrm{CO})_{5}$ to a flame, and other support materials are desired.

There is a theoretical basis for believing that zeolite-NaY would be a more desirable support material than would be zeolite-NaX. The surface physical-chemical properties of the zeolite likely have an important role in the $\mathrm{Fe}(\mathrm{CO})_{5}$ decomposition process. The general formula for a unit cells of zeolite is given by $\mathrm{Na} \_x A l \_x S i \_(192-x) O \_384 . y H \_2 O$, where $x$ ranges from 48 to 74 for zeolite $\mathrm{Y}$ and from 74 to 96 for zeolite $\mathrm{X}$. While the cage structure of zeolite-NaX and $\mathrm{NaY}$ is similar, the difference between them is in the content of cation $\mathrm{Na}^{+}$in the solid matrix, so that zeolite-NaY has less $\mathrm{Na}^{+}$than -NaX. This leads to weaker internal electric fields in zeolite$\mathrm{NaY}$ than for zeolite-NaX, and hence less propensity for decomposition of the $\mathrm{Fe}(\mathrm{CO})_{5}$ in zeolite-NaY than in zeolite-NaX. Hence, absorption experiments were also conducted with zeolite-NaY. When exposed to air, however, the $\mathrm{Fe}(\mathrm{CO})_{5}$-absorbed zeolite-NaY also indicated similar $\mathrm{Fe}(\mathrm{CO})_{5}$ decomposition characteristics, but the intensity of the observed reaction appears to be much slower than with zeolite-NaX. In contrast, tests with porous silica particles gave weak indication of $\mathrm{Fe}(\mathrm{CO})_{5}$ decomposition.

Besides porous silica particles, aerogel particles synthesized at University of Virginia were also tested as a possible support material. These particles were formed by hydrolysis of tetrathyl orthosilicate $\left(\mathrm{Si}\left(\mathrm{OC}_{2} \mathrm{H}_{5}\right)_{4}\right)$ in ethanol, followed by drying to remove extra ethanol and water, leaving behind a solid matrix which is $96 \%$ porous. Three $\mathrm{Fe}(\mathrm{CO})_{5}$ absorption experiments were conducted with the aerogel particles produced using the apparatus in Figure 1. Prior to absorbing $\mathrm{Fe}(\mathrm{CO})_{5}$, the aerogel particles were heated to $200{ }^{\circ} \mathrm{C}$ to $250{ }^{\circ} \mathrm{C}$ to remove as much moisture as possible. The first sample indicated a particle mass increase of about $200 \%$. Two subsequent absorption experiments with aerogels, however, indicated $\mathrm{Fe}(\mathrm{CO})_{5}$ absorption of $14 \%$ and $101 \%$ of the aerogel particle mass. (Note that the second sample was from the same batch of aerogel as the first, while the third sample was from a newly synthesized batch of aerogel). Furthermore, both the second and third samples reacted after about 5-10 minutes exposure to air, while the first sample with substantially large increase in mass (about $200 \%$ ) did not react when exposed to air for a long period of time.

The decreased uptake of $\mathrm{Fe}(\mathrm{CO})_{5}$ in the second and third aerogel samples and the subsequent reaction when exposed to air lead us to believe that either water or ethanol in the aerogel (from the synthesis process described above) was not completely removed. Since $\mathrm{Fe}(\mathrm{CO})_{5}$ is known to react violently with water, the absorbed water is perhaps the most likely cause for the above discrepancy in $\mathrm{Fe}(\mathrm{CO})_{5}$ absorption and its decomposition. 


\subsubsection{Quantification of $\mathrm{Fe}(\mathrm{CO})_{5}$ Absorption/Desorption}

A standard technique for measuring the desorption or the decomposition properties of materials is thermogravimetric analysis TGA. In these tests, the sample is continuously weighed, while its temperature is increased. The TGA analyses required transferring of the $\mathrm{Fe}(\mathrm{CO})_{5}$ absorbed particles from the absorption flask to the weighing pan of the TGA. During this process, some fraction of the particles can react with ambient air, especially those with zeolite and alkali carbonates as support material. Minimizing the time involved in this transfer process, and hence exposure to air, TGA analysis were performed for all of the absorbed particles. In the case of $\mathrm{Fe}(\mathrm{CO})_{5}$-absorbed aerogel particles, the sample did not react immediately when exposed to air, hence the desorption of $\mathrm{Fe}(\mathrm{CO})_{5}$ from the aerogel particles measured via TGA is probably the most reliable. However, the desorption of $\mathrm{Fe}(\mathrm{CO})_{5}$ from aerogels showed a great variation depending on the sample used. For example, some aerogel samples showed as little as $5 \%$ desorption while the maximum detected was $200 \%$. In the case of zeolites, silica and aerogels, the sample were heated up to about $500{ }^{\circ} \mathrm{C}$ in steps of $5{ }^{\circ} \mathrm{C} / \mathrm{min}$, while $\mathrm{NaHCO}_{3}$ and $\mathrm{Na}_{2} \mathrm{CO}_{3}$ were heated only to $150{ }^{\circ} \mathrm{C}$ because of their propensity to decompose. Based on the TGA data, Table 1 shows, in the second column, the weight loss observed of all the particles considered. It is not clear whether the observed weight loss is due to desorption of undissociated $\mathrm{Fe}(\mathrm{CO})_{5}$ or decomposed carbonyl, which may describe the discrepancy with some of the elemental analysis data presented below.

Table 1 - Summary of the Fe mass fraction in Unheated and Heated particles.

\begin{tabular}{|c|c|c|c|c|c|}
\hline \multirow[b]{3}{*}{ Support Material } & \multirow{3}{*}{$\begin{array}{c}\text { From TGA } \\
F e \%(b y \text { mass }) \\
\text { Heated }\end{array}$} & \multicolumn{4}{|c|}{ From Elemental Analysis } \\
\hline & & \multicolumn{2}{|c|}{$\mathrm{Fe} \%$ (by mass) } & \multicolumn{2}{|c|}{$\mathrm{Na} \%$ (by mass) } \\
\hline & & Unheated & Heated & Unheated & Heated \\
\hline Zeolite-NaX & $7.1 \pm 0.7$ & $8.9 \pm 0.9$ & $7.1 \pm 0.7$ & $11.0 \pm 1.1$ & $9.8 \pm 1.0$ \\
\hline Zeolite-NaY & $7.1 \pm 0.7$ & $9.7 \pm 1.0$ & & $6.8 \pm 0.7$ & \\
\hline Porous Silica & $6.0 \pm 0.6$ & $12.8 \pm 1.3$ & $6.8 \pm 0.7$ & $<0.8$ & $<0.1$ \\
\hline Silica Aerogel & 4 to 57 & & & & \\
\hline $\mathrm{NaHCO}_{3}$ & $5.0 \pm 0.5$ & $<0.1$ & $<0.2$ & $28.0 \pm 2.8$ & $41.0 \pm 4.1$ \\
\hline $\mathrm{Na}_{2} \mathrm{CO}_{3}$ & $2.0 \pm 0.2$ & & & & \\
\hline
\end{tabular}

Elemental analysis was performed (by Southern Testing and Research Laboratories ${ }^{2}$ ) to quantify the amount of $\mathrm{Fe}$ (and $\mathrm{Na}$ ) in absorbed and reacted particles (after exposing to air). Table 1 lists the support matrix in the first column, with the mass fraction of Fe in the sample after exposure to $\mathrm{Fe}(\mathrm{CO})_{5}$, based on the weight loss of the sample in the TGA measurements, in the second column. The third through fifth columns provide the results of the elemental analysis for Fe and Na. These data are presented for the two cases: unheated and heated particles. The heated

\footnotetext{
${ }^{2}$ Certain commercial equipment, instruments, materials or vendors are identified in this paper to adequately specify the procedure. Such identification does not imply recommendation or endorsement by the National Institute of Standards and Technology, nor does it imply that the materials or equipment are necessarily the best available for the intended use.
} 
particles were raised to $500{ }^{\circ} \mathrm{C}$ in air for several hours to ensure that $\mathrm{Fe}(\mathrm{CO})_{5}$ was fully decomposed.

Comparison of the elemental analyses for the two cases indicates that heating of the reacted particles had a small effect on the absorbed Fe level for zeolite particles, but a larger effect for porous silica particles. Hence, it appears that any Fe remaining in the zeolite particles was no longer intact $\mathrm{Fe}(\mathrm{CO})_{5}$ that could be liberated by heating, but rather, was already decomposed. For porous silica, about half of the $\mathrm{Fe}(\mathrm{CO})_{5}$ was decomposed or unavailable for liberation by heating. Interestingly, the mass fractions $\mathrm{Fe}$ - and $\mathrm{Na}$-atoms in zeolite are considerable and are very similar. If the $\mathrm{Na}$ could be liberated from the zeolite particles in the flame, they might provide flame inhibition even without added iron.

In order to determine whether any unreacted $\mathrm{Fe}(\mathrm{CO})_{5}$ remained inside the particle after exposure to air, infrared (IR) spectroscopy analysis was performed. The reacted zeolite or porous silica particles were crushed and then mixed with potassium bromide particles. This mix is then pressed to form a thin wafer and then tested in the IR spectrometer. A search for the Fe-CO stretching bond (characteristic of $\mathrm{Fe}(\mathrm{CO})_{5}$ ) indicated that these was little $\mathrm{Fe}(\mathrm{CO})_{5}$ remaining in the solid support matrices.

The $\mathrm{Fe}(\mathrm{CO})_{5}$-impregnated and reacted zeolite particles were also analyzed using the highresolution transmission electron microscope (HRTEM). Images of zeolite-NaY particles after absorption of $\mathrm{Fe}(\mathrm{CO})_{5}$ and exposure to air showed that a condensed-phase substance formed on the exterior surface. For example, Figure 2 shows an image of a zeolite particle after $\mathrm{Fe}(\mathrm{CO})_{5}$ was absorbed and then the sample exposed to air, while for comparison, Figure 3 shows an image of a pure zeolite particle. In Figure 2, the zeolite-NaX particle is shown to have a diameter on the order of a micrometer, with pore sizes of the order of $1 \mathrm{~nm}$, while nodules of condensed-phase material (likely $\mathrm{Fe}, \mathrm{FeO}$, or perhaps even $\mathrm{Fe}_{2} \mathrm{O}_{3}$ ) have diameters of about 20 $\mathrm{nm}$, and are rather well dispersed on the support material. The main purpose of this investigation was to obtain qualitative information about the nature of the absorbed agent. The formation of these condensed-phase nodules implies that $\mathrm{Fe}(\mathrm{CO})_{5}$ may not be available from the matrix to provide gas-phase $\mathrm{Fe}$, which is required for efficient flame inhibition. 


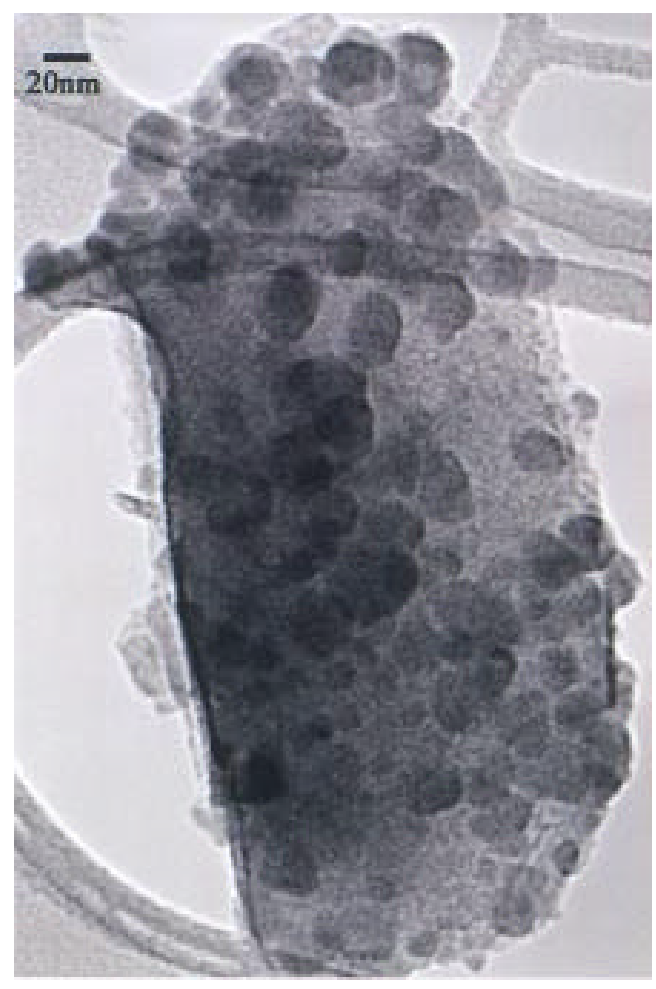

Figure 2 - High resolution transmission electron micrograph image of Zeolite-NaX particle with condensed phase iron species on surface.

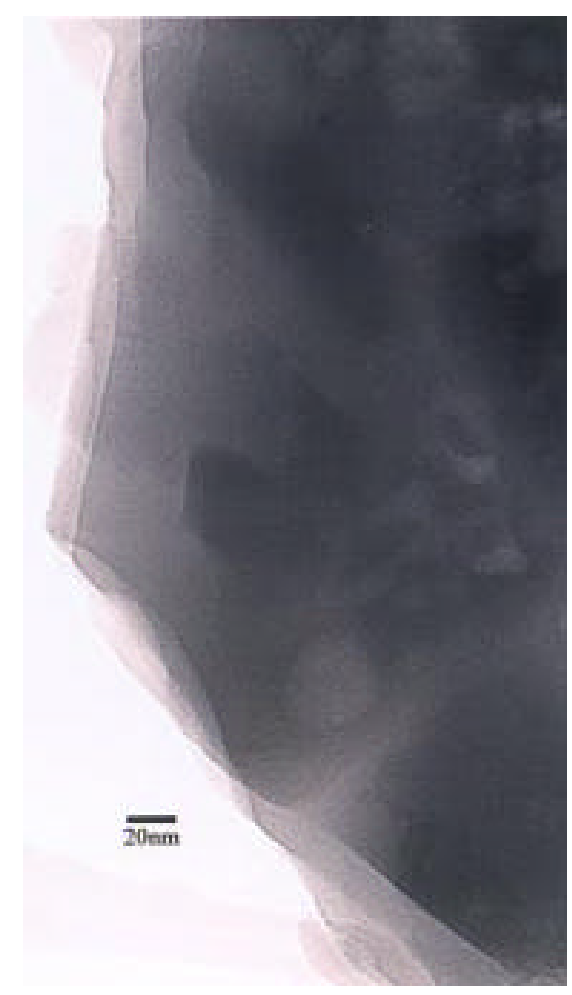

Figure 3 - Pure zeolite-NaX, without $\mathrm{Fe}_{2} \mathrm{O}_{3}$ clusters.

\subsubsection{Surrogate Agents for Absorption/Desorption Testing}

With the unexpected difficulties associated with $\mathrm{Fe}(\mathrm{CO})_{5}$ decomposition within the solid support material, the possibility of using other chemical compounds to quickly test the encapsulation concept was pursued during the last year. Because of previous experience in adsorption/desorption of iodine in zeolite particles, iodine was selected as a suitable, safe compound to handle in the laboratory. Recent absorption/desorption investigations have indicated that an iodine mass fraction of about $24 \%$ can be loaded into zeolite-NaX particles, while about $6 \%$ mass fraction of $\mathrm{I}_{2}$ can be loaded into the milled and sized (10 $\mu \mathrm{m}$ to $20 \mu \mathrm{m}$ size range) crystalline silica particles. Here, crystalline silica particles were considered because of their better fluidization and seeding characteristics. In addition, absorption of iodine in the porous silica gel particles (used in above flame studies) has been carried out. To quantify the amount of iodine loaded into these particles, TGA analyses were performed on two samples. One set of particles was tested immediately after the absorption process and the other, after the particles had remained in the airflow of the fluidization seeder for several hours. The TGA analysis on the fresh particles indicated a mass loss of $19 \%$, while that on the particles out of the seeder after the experiments indicated a mass loss of about $8 \%$. We also noted a change in the particle color (to a lighter brown shade) after they were in the seeder for several hours, a result consistent with the lower mass loss for the post-seeder particles. 


\subsection{Methods of Quantifying Suppression Effects by Particulates}

In order to determine the effectiveness of particles impregnated with super-effective catalytic inhibitors, it is first necessary to have a method to add particles to the appropriate flame. To this end, we have designed, built, and tested an effective particle seeding system for introduction of the $\mathrm{NaHCO}_{3}$, silica, zeolite, or aerogel particles to both counterflow diffusion flames and premixed Bunsen-type flames. The particle seeder designed was modular in nature and could be easily adapted to either flame. While development of the seeder took much time and care, it was critical for the ultimate success of this investigation. Although this delayed some of the other tasks of the project, the results have been broadly useful to other NGP researchers who are now basing their designs on that developed here. We first describe the counterflow burner and particle seeding system, followed by a description of the premixed burner and LDV system and the conclusions for this section. Sodium bicarbonate and silica particles were used as the test cases for development of the seeding and burner systems, and the results for those materials are presented below.

Two burner types were selected as test beds for the particles: a premixed Bunsen-type nozzle burner, and a gaseous counterflow diffusion flame burner, also with nozzle-generated flows. These flames were selected for several reasons. First, and foremost, unlike co-flow diffusion flames burners (such as cup-burner flames), they both allow unambiguous determination of the amount of agent with reaches the relevant high-temperature reaction region of the flame. In contrast, it is difficult in cup-burner flames to determine the amount of agent which actually makes it to the region of the flames where it is need to extinguish the flame. These values are difficult to obtain for a cup-burner since the transport of agent or particles to the appropriate region of the cup-burner is complex; moreover, stabilization (and therefore extinction) of cupburner flames is not presently well understood theoretically. Further, cup-burner flames allow tests at only one strain rate; whereas, counterflow diffusion flames allow tests at variable strain rates. We originally planned to do tests only in the counterflow diffusion flames. As we gained experience working with particles, however, we became aware of the danger of $\mathrm{Fe}(\mathrm{CO})_{5^{-}}$ impregnated particles contaminating the laboratory space. Because premixed flames involved much smaller quantities of gas and particles, and since all of the reactants pass through a flame, they were believed to provide a safer configuration for the tests. Since premixed flames directly provide a measure of the overall reaction rate in the flame, results in those flames should be directly comparable to those in a counterflow diffusion flame. As discussed below, Peters has shown [15], from a theoretical basis, that the performance of a chemical catalytic inhibitor in premixed and counterflow diffusion flames should be correlated. Most importantly, either one should provide a direct measure of the effect of an agent on the overall reaction rate in the flame, in a configuration which is easily interpreted or modeled. The development of these two test beds for experiments with particles is described below. 


\subsubsection{Counterflow Diffusion Flames with Inert and $\mathrm{NaHCO}_{3}$ Particles}

\subsubsection{Experiment}

A steady, planar, non-premixed flame was established in the mixing layer of counterflowing methane and air streams. Figure 4 shows the experimental setup of the counterflow burner. The fuel and air nozzles are made from Pyrex glass. The exit diameter of the inner tubes is $15 \mathrm{~mm}$ with a nozzle area contraction factor of 6.5 , producing a nearly plug flow velocity profile at the nozzle exit. The co-annular nitrogen streams on both fuel and air sides help maintain a stable planar flame disk. The cylindrical burner chamber includes provision for dilution of the chamber with room air at the bottom (to minimize the occurrence of secondary flames), water cooling, and easy adjustment of the nozzle separation distance via o-ring sealed vacuum fittings (MDC). The typical separation distance between the two nozzles is $10 \mathrm{~mm}$ to $12 \mathrm{~mm}$. The exhaust gases were evacuated using an air-driven mass flow ejector, with the chamber pressure monitored by a differential pressure gauge. The methane was BOC grade 4.0 with a purity of $99.99 \%$. The air was supplied by an oil-free compressor and dried by a series of dessicant beds. The flow rates of fuel and air were controlled using factory-calibrated mass flow meters (Teledyne HastingsRaydist), with a reported accuracy of $\pm 1 \%$.

\subsubsection{Particle Seeder:}

Because of the challenge in verifying the accuracy of previously reported data with $\mathrm{NaHCO}_{3}$ particles $[16,17]$, considerable attention was devoted to the development of a particle seeder that could provide steady feed rates of particles of various diameters (i.e., from $2 \mu \mathrm{m}$ to $100 \mu \mathrm{m}$ ). For the small air flows involved (typical flows of $0.1 \mathrm{~L} / \mathrm{s}$ ), the fluidized bed approach shown in Figure 4 gave satisfactory seeder performance only for relatively small particles, i.e., less than 30 $\mu \mathrm{m}$. This fluidized bed seeder consists of a $19 \mathrm{~mm}$ diameter glass tube with two porous plugs at either end. The air flow to the seeder is controlled through a mass flow controller and split into two streams, which are connected to either end of the glass tube. The flow passing through the bottom, which controls the fluidization level, is monitored through another flow controller. The fluidized particles and the air entering the fluidization tube (from the top and bottom) is extracted through a small tube located near the middle of the tube. By maintaining the total air flow to the fluidizer tube constant, the particle feed rate is steady, and this is verified by continuously monitored the light scattered from the particle stream, as shown in Figure 4. The detection system consists of a laser diode $(671 \mathrm{~nm})$, a high speed silicon detector (Thor Labs DET1-SI ) with a $3 \mathrm{~cm}$ focal length collection lens, laser line filter at $671 \mathrm{~nm}$ (Edmund Scientific), and a strip chart recorder (Hewlett-Packard Model 7132) to monitor the detector output. 


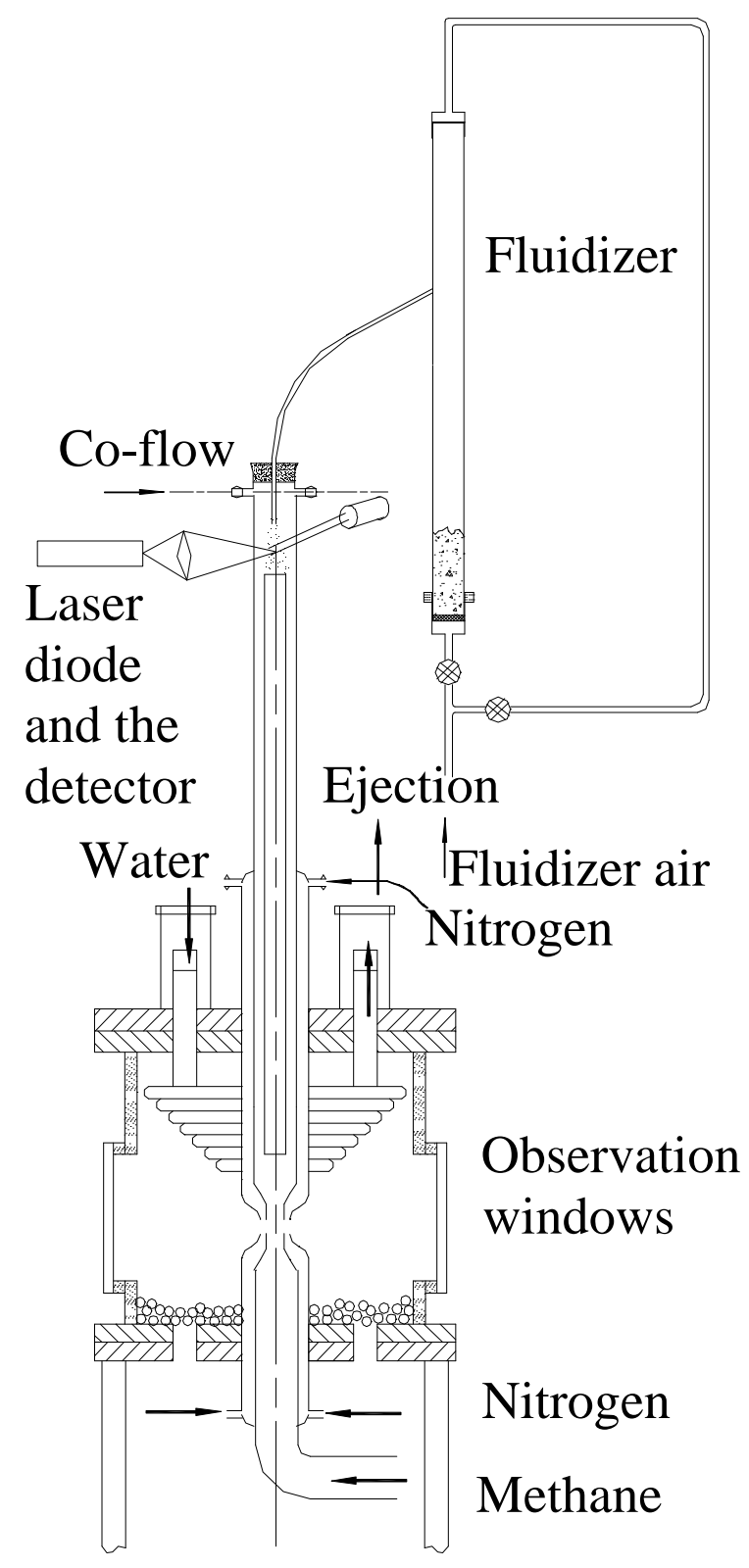

Figure 4 - Schematic diagram of counterflow diffusion flame burner with provision for addition of particles to air stream.

\subsubsection{Results}

Figure 5 shows an image of a typical flame disk established without and with $\mathrm{NaHCO}_{3}$ particles. Experiments have been conducted to establish the effectiveness of particle size on non-premixed flame suppression. These results are shown in Figure 6 as the mass fraction of $\mathrm{NaHCO}_{3}$ needed vs. flow strain rate at extinction, for particle sizes $10 \mu \mathrm{m}$ to $20 \mu \mathrm{m}, 20 \mu \mathrm{m}$ to $30 \mu \mathrm{m}, 30 \mu \mathrm{m}$ to 40 
$\mu \mathrm{m}$, and $40 \mu \mathrm{m}$ to $60 \mu \mathrm{m}$. For comparison, the effectiveness of $10 \mu \mathrm{m}$ to $20 \mu \mathrm{m}$ crystalline silica particles are also shown. It is clear that $\mathrm{NaHCO}_{3}$ particles below 20 microns are significantly more effective in this flow field. As the $\mathrm{NaHCO}_{3}$ particle size increases, the performance approaches that of the inert silica particles.
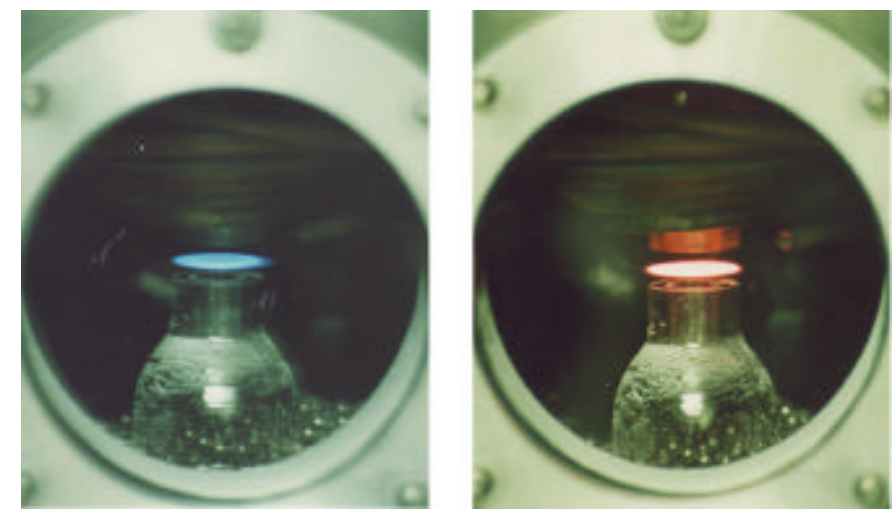

Figure 5 - Methane-air counterflow diffusion flame pure (left), and with $\mathrm{NaHCO}_{3}$ particles (right).

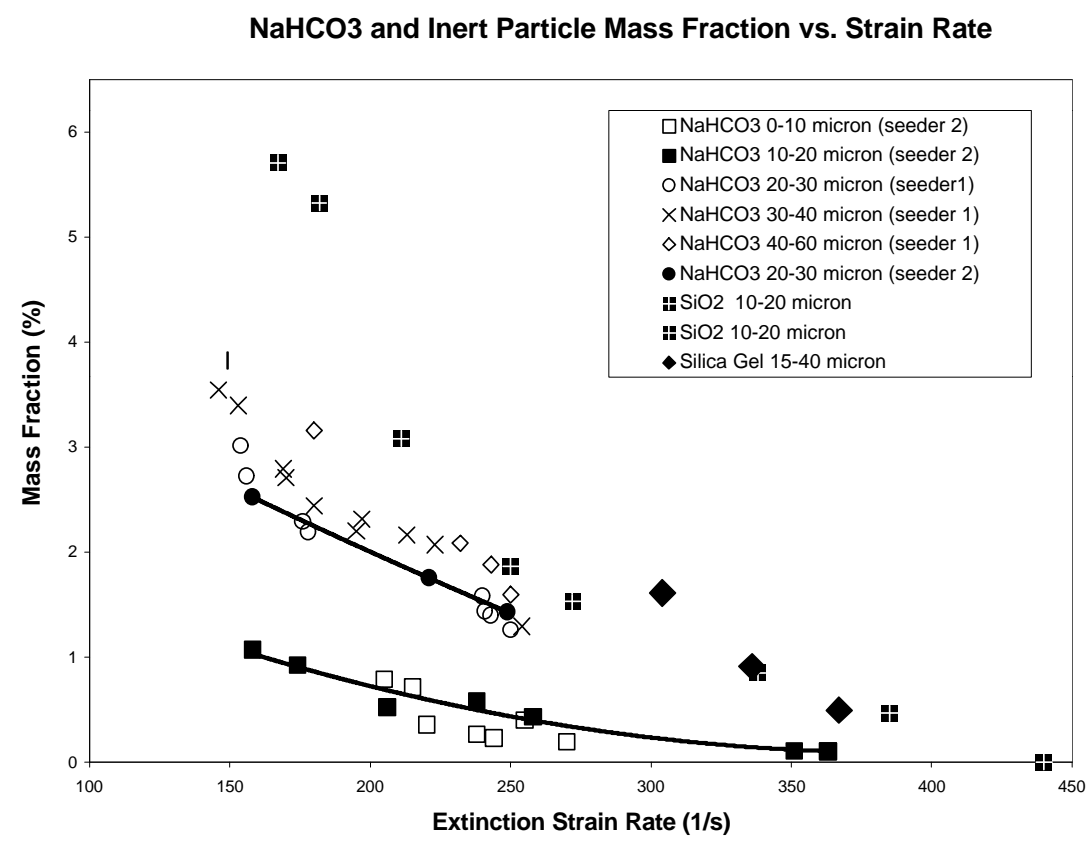

Figure 6 - $\mathrm{NaHCO}_{3}$ and Silica mass fraction vs. methane-air nonpremixed extinction strain rate.

Figure 7 shows two photographs of the crossed laser beams from an LDV system penetrating a non-premixed counterflow methane-air flame seeded with $40 \mu \mathrm{m}$ to $60 \mu \mathrm{m} \mathrm{NaHCO}_{3}$ particles. In the upper image, the beams are above the flame, in the region between the flame and the incoming air stream (which is laden with particles), so that the particles have not yet reached the 
flame. Laser scattering from the particles is clearly visible. In the lower image, the beams are located below the flame and there is still obvious laser light scattering, indicating these large particles survive through the flame. This behavior results in the lower suppression effectiveness as illustrated in Figure 6. These results also indicate that even inert particles tend to reduce the flame extinction rate with increasing particle loading. Such effects can be related to the thermal effects associated with heating of these inert particles.

Parallel modeling efforts have shown that by selecting an appropriate value for the particle decomposition temperature, the experimental results shown in Figure 6 can be mimicked. With a fixed particle decomposition temperature, the trends observed in Figure 6 for the variation in effectiveness due to particle size can then be captured. The basic outcome of such modeling results is that the existence of a critical particle size which is effective in this flow field is directly related to the flow residence time, hence the heating of the particle and its decompositions rate, which would ultimately control the chemical effectiveness.
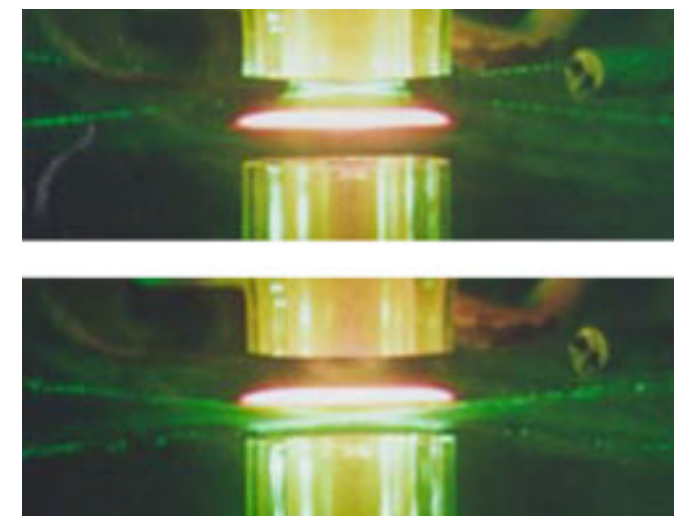

Figure 7 - Laser Doppler velocimetry measurements of $\mathrm{NaHCO}_{3}$ particles in a counterflow diffusion flame of methane and air, showing that the particles pass through the flame. The two images show laser scattering (bright green) when the probe beams are directed either above or below the flame (indicated by the bright orange emission from sodium).

\subsubsection{Premixed Flames with Inert and $\mathrm{NaHCO}_{3}$ Particles}

Premixed flames afford a clear measure of the effect of an inhibitor on the overall reaction rate while also providing a safe, convenient system for controlling the release of toxic particles. Since there is a theoretical basis for relating the performance of an inhibitor in premixed flames to that in counterflow diffusion flames [15], we pursued flame inhibition tests in premixed Bunsen-type flames as described below.

\subsubsection{Experiment}

A Mache-Hebra nozzle burner $(1.5 \mathrm{~cm} \pm 0.05 \mathrm{~cm}$ diameter $)$ produces a premixed Bunsen-type flame about $1.9 \mathrm{~cm}$ tall with a straight sided schlieren image that is captured by a CCD array camera connected through a USB port to a PC. Digital mass flow controllers hold the 
equivalence ratio $\phi$ and the flame height constant while the mass flow of particles from the seeder is set at the desired value. The average burning velocity is determined from the reactant flows and the schlieren image using the flame angle method [18] from the measured velocity profile. The fuel gas is methane (BOC grade 4.0; $99.99 \%$ ), and the oxidizer stream consists of laboratory air from an oil-free compressor which was dried by a series of desiccant beds. Air and fuel gas flows are set by PC-controlled mass flow controllers (Sierra, 860).

\subsubsection{LDV System}

A laser Doppler velocimetry (LDV) system was assembled to establish the quality of the top hat velocity profile leaving the nozzle exit (for both non-premixed and premixed flames) and to measure the local strain rate in the counterflow field. Because the enclosed counterflow burner permitted optical access from the two opposing sides, an on-axis forward scattering LDV configuration was selected. The LDV system consisted of an Argon Ion laser (Lexel Model 95) operating at $514.5 \mathrm{~nm}$ with a beam splitter and $300 \mathrm{~mm}$ focal length transmitting lens (DISA) to obtain two equal intensity beams forming a fringe pattern at the intersection of the focused beams. The probe volume was $0.151 \mathrm{~mm}$ wide and $1.51 \mathrm{~mm}$ long, with a fringe spacing of 2.57 $\mu \mathrm{m}$. The collection optic system (DISA) gathered the forward scattered photons from the particles and imaged them on a photomultiplier tube (PMT). The PMT current was amplified (C-Cor Electronics Model 4375A Wideband Video Amplifier) and processed by a timer/counter (TSI Model 1990B) operated in the single burst mode using 8 cycles/burst. The filtered and amplified timer/counter signal was monitored by an oscilloscope (Tektronix Model 2212), and the digital output was interfaced to a personal computer using a digital input card (National Instruments DAQ pad 6510) and processed using data aquisition software (LabView). Measured frequencies were related to particle velocity using the known fringe spacing. To facilitate acquisition of velocity profiles in axial and radial direction of the counterflow field, both fringe generating and collecting optics were mounted on translation stages (Velmex Unislide Model MB2500), which have a minimum step size of $1 \mu \mathrm{m}$, with a reported accuracy of $5 \mu \mathrm{m}$ in 100 $\mathrm{mm}$. Figure 8 shows typical velocity profiles at the exit of the premixed burner nozzle, for two different volume flow rates. For comparison, the calculated top-hat velocity profiles are also shown as dotted lines. 


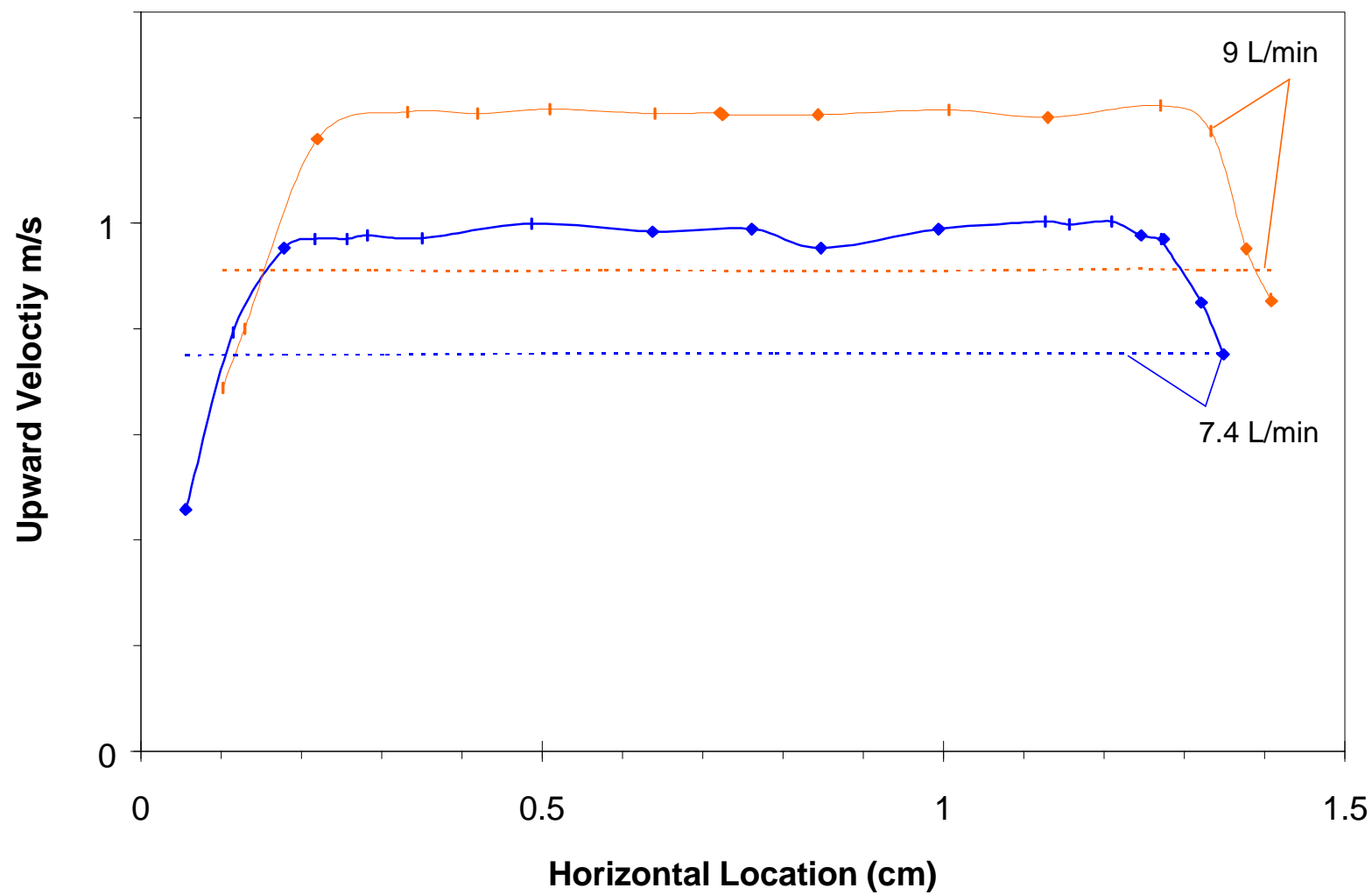

Figure 8 - Calculated (dotted lines) and LDV-measured (points) velocity profiles at exit of premixed burner nozzle for total flow rates of 7.4 and $9 \mathrm{~L} / \mathrm{min}$.

\subsubsection{Results}

We characterized the performance of the premixed burner through flame speed measurements in the presence of silica, zeolite, and sodium bicarbonate particles. Unfortunately, few data were available in the literature for comparison with the present data. Figure 9 shows this burner operating with methane-air, with and without $\mathrm{NaHCO}_{3}$ particles added to the reactant flow. Extraction of the burning velocity information from this setup requires obtaining the flame surface area or the cone angle. A schlieren system allowed determination of the flame area for conditions with a high background visible radiation (e.g., blackbody radiation with inert particles or sodium D-line emission with $\mathrm{NaHCO}_{3}$ or zeolite). The burner exit velocity was characterized using an LDV system. A comparison of the normalized burning velocity obtained for various particles tested are shown in Figure 23. The results clearly indicate that the inert silica particles and zeolite- $\mathrm{NaX}$ have a minor effect on the measured burning velocity, while $\mathrm{NaHCO}_{3}$ has a noticeable effect on the burning velocity. 


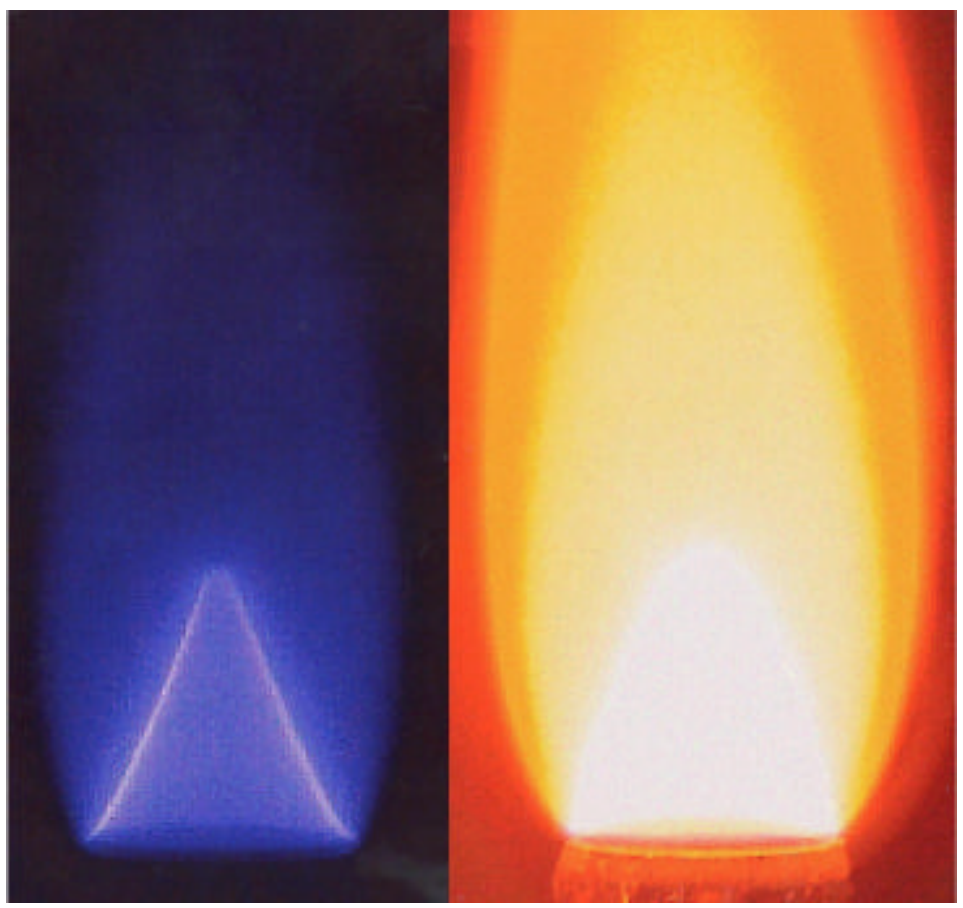

Figure 9 - Premixed methane-air nozzle burner flame pure (left) and with $\mathrm{NaHCO}_{3}$ particles (right).

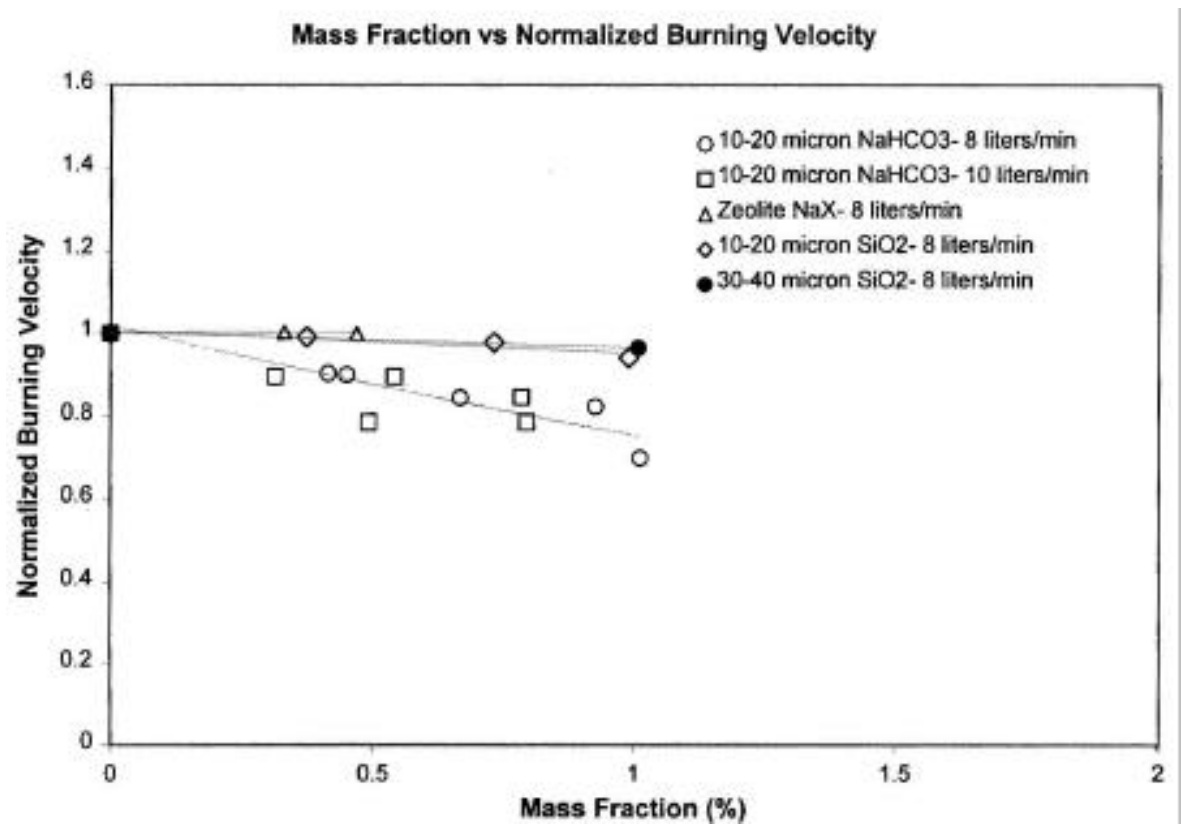

Figure 10 - A comparison of reduction of normalized burning velocity with mass fraction of silica, $\mathrm{NaHCO}_{3}$, and zeolite particles. 
Comparison of the relative reduction of normalized, non-premixed flame extinction strain rates with normalized premixed burning velocities indicates significant differences. However, such comparisons should take into account the structural differences of the two flames. As shown by Peters [15] and employed by Chelliah et al. [19] for chlorinated hydrocarbon flames, the normalized burning rate is related the normalized extinction strain rate as $S_{L} / S_{L, 0}=\sqrt{ }\left(a_{\text {ext }} / a_{\text {ext, } 0}\right)$

Using this correlation, the modified comparison of the non-premixed and premixed flames inhibited with $\mathrm{NaHCO}_{3}$ is shown in Figure 11. The disagreement between the two is somewhat greater than the uncertainty in each measurement; however, this disagreement is much less than one might expect based on the significantly different structures of the premixed and diffusion flames. Hence, we expect that tests with either flame should be roughly comparable in demonstrating the effectiveness of chemically acting agents on the global reaction rate in methane-air flames. On the other hand, the data for inert particles in premixed and counterflow diffusion flames from Figure 6 and Figure 10, if plotted in Figure 11 would show a significant discrepancy. Most likely, these differences are related to the thermal effects associated with varying particle residence time in the two flows considered, and further analysis is required.

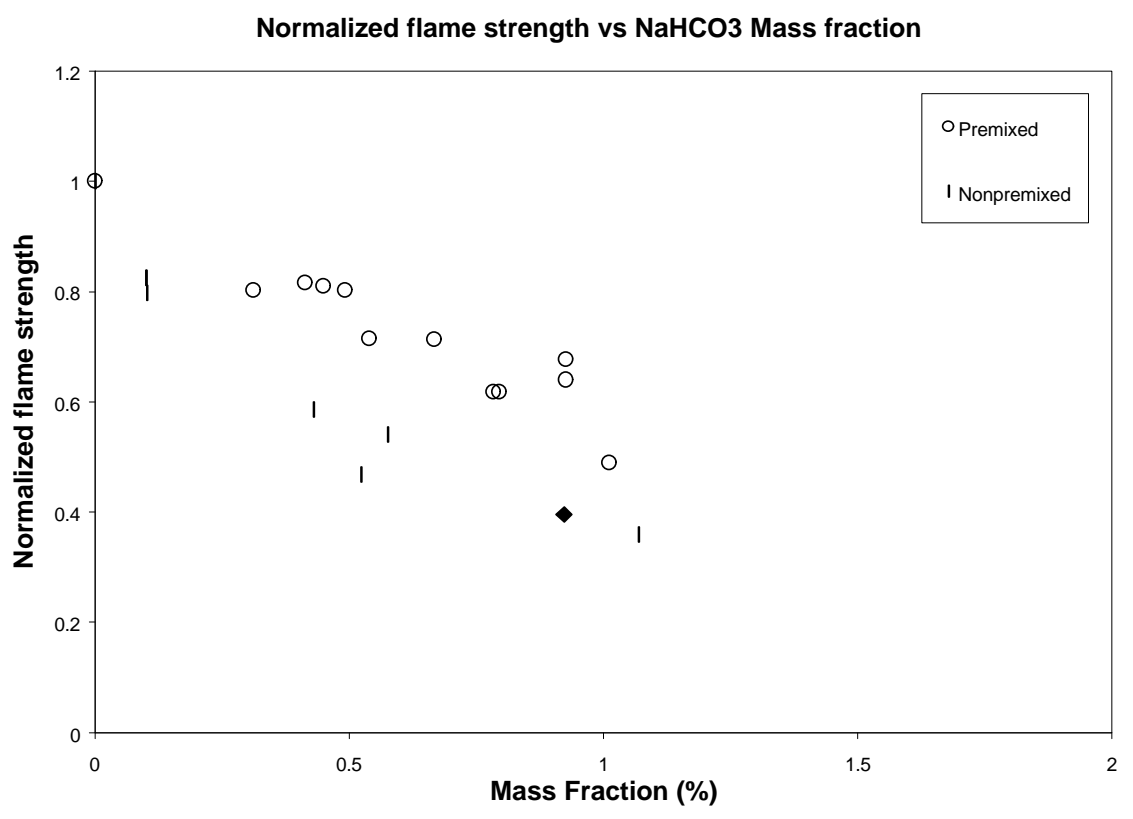

Figure 11 - Normalized flame strength as a function of added $\mathrm{NaHCO}_{3}$ mass fraction for premixed and counterflow diffusion flames.

As discussed below, recent experiments with iron species in cup-burner flames did not indicate much benefit. Hence, for these chemicals in actual fires, there may not be much utility to their encapsulation. Another option is to test the technique with known, effective halogens such as $\mathrm{I}_{2}$ or $\mathrm{Br}_{2}$. Experiments of this type were conducted, and are discussed below. The key features, aside from the rate of release of the agent from the matrix, are the mass of $\mathrm{I}_{2}$ or $\mathrm{Br}_{2}$ required, and the fractional holding capacity of the matrix. 


\subsubsection{Conclusions}

The fluidized-bed seeding system described above is effective for introducing particles of less than $30 \mu \mathrm{m}$ to the premixed and counterflow burners. The experimental techniques developed are amenable to testing the efficacy of particles with absorbed super-agents in these flames. Premixed and counterflow diffusion flames have the advantage in that they can directly provide a measure of the effect of the particles on the overall reaction rate of the fuel-air mixture. We have determined, however, that in these flames, the effectiveness of particles (which either decompose or release an absorbed agent) is dependent upon the residence time for this process. For example, the effectiveness of the sodium bicarbonate as a flame inhibitor was seen to be dependent upon the size of the particles. The correlation between the performance of $\mathrm{NaHCO}_{3}$ in premixed and counterflow diffusion flames was close, although there was significant discrepancy which was likely due to the different residence times for particle decomposition in each of the two flame configurations.

\subsubsection{Premixed Flames with lodine}

Since particles in the laboratory tend to be ubiquitous, there was some concern about safety of seeding particles embedded with $\mathrm{Fe}(\mathrm{CO})_{5}$ into a counterflow diffusion flame. Premixed flames have much smaller flows, and all of the reactants pass through the flame, increasing the likelihood of decomposing $\mathrm{Fe}(\mathrm{CO})_{5}$ in the particles. Hence, premixed flames were selected for the first tests of agent-impregnated particles. The NGP executive committee recommended tests with $\mathrm{CF}_{3} \mathrm{I}$ as a surrogate for $\mathrm{Fe}(\mathrm{CO})_{5}$ in order test the concept. Since iodine $\mathrm{I}_{2}$ would be expected to be about twice as effective as $\mathrm{CF}_{3} \mathrm{I}$, we decided to use it rather than $\mathrm{CF}_{3} \mathrm{I}$ in these tests.

Selection of the appropriate matrix material for the particles was based on agent mass loading potential and the seeding properties of the particles in the flow. With the zeolite-NaX, maximum particle seeding achievable with the present apparatus used in the premix flame configuration is about $0.5 \%$ by mass (because of very small size, $2 \mu \mathrm{m}$ ). On the other hand, in the same premixed flame configuration, more than $2 \%$ by mass of sized $10 \mu \mathrm{m}$ to $20 \mu \mathrm{m}$ crystalline silica particles can be introduced, yielding a similar iodine loading. These limitations, together with the mass fraction of $\mathrm{I}_{2}$ absorbed into the particle, limit the mass fraction of $\mathrm{I}_{2}$ which can be added to the flame to about $0.12 \%$. With silica gel particles $(15 \mu \mathrm{m}$ to $40 \mu \mathrm{m})$, however, with much higher particle seeding (up to $6 \%$ particle mass) and about $20 \%$ iodine mass loading, the resultant theoretical iodine mass delivery can approach as high as $1.2 \%$ in a flame environment. Therefore, premixed flame inhibition experiments were conducted only with iodine absorbed silica gel particles. Figure 12 shows the normalized flame speed of a methane-air flame for increasing particle mass fraction, for pure silica gel and $\mathrm{I}_{2}$-impregnated silica gel. As seen from this figure, iodine absorbed silica particles do not show any significant reduction in burning velocity compared to chemically inert silica particles.

Based on literature values of the burning velocity reduction of $\mathrm{Br}_{2}$ in hydrocarbon flames [20], we estimate that an $\mathrm{I}_{2}$ mass fraction of $10 \%$ would be required to reduce the burning velocity by a factor of two. Hence, even if all of the $I_{2}$ in the silica gel particles (estimated to be a mass fraction of 0.20 ) were liberated in the flame, the maximum expected burning velocity reduction would be about $5 \%$ for a $6 \%$. In the present experiments, with very high particle seeding, such 
a difference in burning velocity may be difficult to detect; for lower iodine desorption rates, difference with and without $\mathrm{I}_{2}$ would be even harder to see.

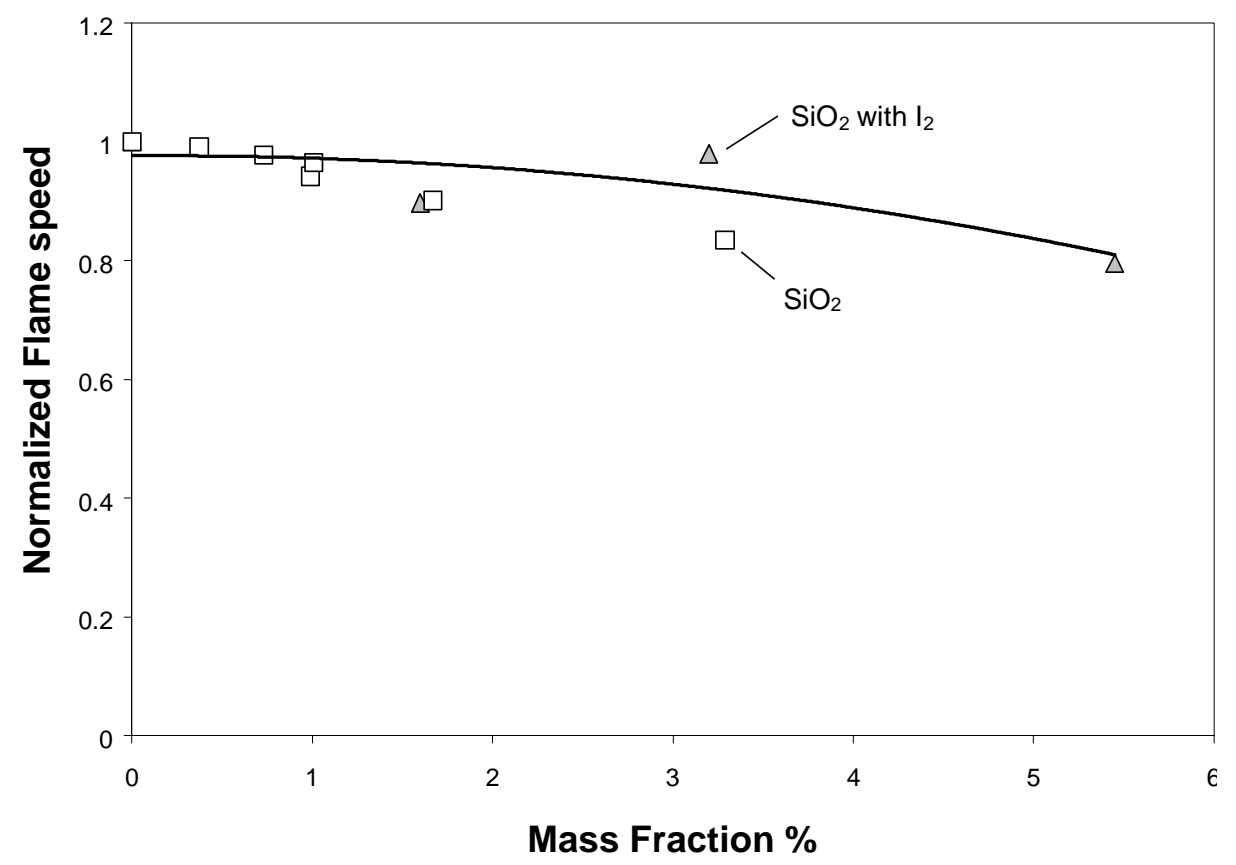

Figure 12 - Normalized flame speed for a methane-air flame with added silica gel particles $(14$ to 40$) \mu \mathrm{m}$, with and without $I_{2}$ impregnated in the particles.

\subsection{Complexation of Super-Effective Metals}

\subsubsection{Super Agents and Complexing Ligands Considered}

As a first step, the physical and chemical properties of complexes of potential agents were compiled and surveyed. The complexes involved main-group or metal-centered with different ligands. Organic ligands included the following: 1. acetate (ac), acetylacetate (acac), oxalate; 2. trifluoroacetylacetate (TFacac), hexafluoroacetylacetonate (Hfacac); 3. methoxide (OMe), ethoxide $(\mathrm{OEt})$. The halide ligands: chlorine $(\mathrm{Cl})$, bromine $(\mathrm{Br})$, and iodine $(\mathrm{I})$ were also considered. The main-group centered compounds included 1. Group III - aluminium (Al); 2. Group IV - tin (Sb), germanium $(\mathrm{Ge})$, lead $(\mathrm{Pb})$; 3. Group V - antimony (Sb). Metal-centered compounds included the following classes: 1. copper $(\mathrm{Cu}) ; 2$. titanium $(\mathrm{Ti}) ; 3$. chromium $(\mathrm{Cr})$, molybdenum (Mo); 4. manganese $(\mathrm{Mn})$, nickel $(\mathrm{Ni})$, cobalt $(\mathrm{Co})$; 5. iron $(\mathrm{Fe})$.

For the metal-centered halides, it was found that the three most volatile compounds $\mathrm{MX}_{4}$ were (in order of volatility): $\mathrm{TiX}_{4}<\mathrm{SnX}_{4}<\mathrm{GeX}_{4}$. The bromides become volatile in the range $70{ }^{\circ} \mathrm{C}$ 
to $150{ }^{\circ} \mathrm{C}$, while the chlorides were higher in the range $\left(180{ }^{\circ} \mathrm{C}\right.$ to $\left.240{ }^{\circ} \mathrm{C}\right)$. Germanium iodide was iodide compound with the lowest boiling point - estimated near $350{ }^{\circ} \mathrm{C}$.

For the organic-complexes, it was found that the order of volatility was generally

$$
\text { oxalate }<\text { ac }<\text { acac }<\text { OMe }<\text { OEt }<\text { TFacac }<\text { Hfacac }
$$

Examples of this include $\mathrm{Cr}(\mathrm{HFacac})_{3}$ and $\mathrm{Cr}(\mathrm{ac})_{3}$ that sublime or decompose near $100{ }^{\circ} \mathrm{C}$ to 160 ${ }^{\circ} \mathrm{C}$ and $210{ }^{\circ} \mathrm{C}$ to $280{ }^{\circ} \mathrm{C}$, respectively and $\mathrm{Cu}(\mathrm{HFacac})_{2}, \mathrm{Cu}(\mathrm{TFacac})_{2}$, and $\mathrm{Cu}(\mathrm{acac})_{2}$ that sublime or decompose near $130{ }^{\circ} \mathrm{C}$ to $180{ }^{\circ} \mathrm{C}, 180{ }^{\circ} \mathrm{C}$ to $210{ }^{\circ} \mathrm{C}$, and $290{ }^{\circ} \mathrm{C}$ to $320{ }^{\circ} \mathrm{C}$, respectively.

The relative volatility of complexes was dependent on the metal- or main-group-center atom. The order of volatility for compounds with different ligands varies dependent upon the ligand. Consequently, a direct ordering is not exact. However, in general the volatility was

$$
\mathrm{Al}<\mathrm{Cu}<\mathrm{Mo}<\mathrm{Mn}<\mathrm{Ni}<\mathrm{Cr}<\mathrm{Sn}<\mathrm{Ti}<\mathrm{Fe}<\mathrm{Co}<\mathrm{Sb}<\mathrm{Pb}<\mathrm{Ge}
$$

That is, aluminum and copper compounds were generally significantly less volatile than lead and germanium compounds.

\subsubsection{Selection of Ferrocene}

As described above, there was a wide range of possible choices for complexed metal agents. For our first complexed agent, we chose a compound which contained a known, highly active metal. This limited the metals to $\mathrm{Pb}, \mathrm{Cr}$, and $\mathrm{Fe}$. Because of the high toxicity of $\mathrm{Pb}$ and $\mathrm{Cr}$ in most states and the low toxicity of Fe in its most common forms, we selected iron as the element to try to complex. Previous research has shown that iron atom in the gas phase leads to the inhibiting iron-species intermediates, and that the main property required for the parent molecule is that it readily decomposes at flame temperatures to release iron atom. A possible alternative source of $\mathrm{Fe}$, and the one selected as a the first complexed agent is ferrocene $\left(\mathrm{Fe}\left(\mathrm{C}_{5} \mathrm{H}_{5}\right)_{2}\right.$ or $\left.\mathrm{Fec}\right)$. Ferrocene modifies the sooting tendency of flames [21-26], is added to materials as a flame retardant [27], is an antiknock agent, and is used as a source of iron atoms for kinetic studies. It is also far less toxic than $\mathrm{Fe}(\mathrm{CO})_{5}$.

In this section we present the first measurements of flame inhibition by ferrocene, and compare its performance with that of $\mathrm{Fe}(\mathrm{CO})_{5}$ and $\mathrm{CF}_{3} \mathrm{Br}$ in the same flames. We numerically model Fec's flame inhibition using the iron-species mechanism developed for studies of $\mathrm{Fe}(\mathrm{CO})_{5}$ flame inhibition. Finally, we present results on the performance of Fec in combination with other agents, including $\mathrm{CO}_{2}$, and $\mathrm{CF}_{3} \mathrm{H}$. The present research demonstrates that the efficiency of $\mathrm{Fe}(\mathrm{CO})_{5}$ is not unique, and that there are methods for overcoming its loss of performance. (More details of the work can be found in ref. [28]).

As described above, flame inhibition by highly effective chemical inhibitors has been described in the literature. The inhibition is characterized by several gas-phase radical recombination cycles which proceed at nearly gas-collisional rates. It has been shown that radical 
recombination on particle surfaces is not likely to be fast enough to produce the observed burning velocity reductions at low inhibitor mole fraction [7]. Particle formation is important, however, in that condensation serves as a loss mechanism for the active inhibiting species when their concentration is above the saturation vapor pressure. Additionally, at high enough inhibitor mole fractions, a loss in effectiveness is expected for all catalytic inhibitors since eventually, radical concentrations are lowered to equilibrium levels, and further reduction is not possible. For $\mathrm{Fe}(\mathrm{CO})_{5}$ however, the loss in effectiveness caused by condensation occurs well before the approach to equilibrium of radicals.

Although the present tests are performed in premixed flames of methane, they are relevant to the suppression of practical fires. Methane oxidation is atypical of that of larger hydrocarbons; however, Babushok and Tsang have recently observed [29] that for a wide variety of hydrocarbons, including methane, the burning velocity is most sensitive to the rates of the same reactions. Since these reactions are the ones most influenced by an inhibitor, the trends in inhibitor effectiveness are the same for most hydrocarbons. As has been discussed previously [10], burning velocity measurements are an important first step in assessing an inhibitor's effectiveness and testing mechanism performance. In future research, it is desirable to test these highly-effective agents in flames more closely resembling actual fires.

\subsubsection{Experiment}

The flame speed $S_{L}$ provides a measure of an agent's reduction of the global reaction rate. The experimental arrangement, described in detail previously $[9,10,30]$, has been modified to accommodate a new evaporator for ferrocene and heating of the gas lines and burner tube[28]. A Mache-Hebra nozzle burner $(1.0 \mathrm{~cm} \pm 0.05 \mathrm{~cm}$ diameter $)$ produces a premixed Bunsen-type flame about $1.3 \mathrm{~cm}$ tall with a straight sided schlieren image that is captured by a video framegrabber board in a PC. Digital mass flow controllers hold the oxygen mole fraction in the

oxidizer stream $X_{O 2, o x}$, the equivalence ratio $\phi$, and the flame height constant while maintaining the inlet mole fraction of the inhibitor $\left(X_{i n}\right)$ at the desired value. The average burning velocity is determined from the reactant flows and the schlieren image using the total area method. The fuel gas is methane (Matheson UHP, $99.9 \%$ ), and the oxidizer stream consists of nitrogen (boil-off from liquid $\mathrm{N}_{2}$ ) and oxygen (MG Industries, $\mathrm{H}_{2} \mathrm{O}<50 \mathrm{ppm}$, and total hydrocarbons $<5 \mathrm{ppm}$ ). The inhibitors used are Fec (Aldrich), $\mathrm{Fe}(\mathrm{CO})_{5}$ (Aldrich), $\mathrm{CF}_{3} \mathrm{H}$ (DuPont), $\mathrm{CF}_{3} \mathrm{Br}$ (Great Lakes), $\mathrm{N}_{2}$, and $\mathrm{CO}_{2}$ (Airgas). The $\mathrm{Fe}(\mathrm{CO})_{5}$ is added to $\mathrm{N}_{2}$ carrier gas using a two-stage saturator in an ice bath. Because the vapor pressure of Fec is much lower than that of iron pentacarbonyl, Fec addition at mole fractions up to $650 \mathrm{ppm}$ requires both higher bath temperature $\left(79.1{ }^{\circ} \mathrm{C}\right.$ held within $0.1{ }^{\circ} \mathrm{C}$ ) and higher nitrogen carrier gas flow rates (up to $2800 \mathrm{~cm}^{3} / \mathrm{min}$ ) relative to $\mathrm{Fe}(\mathrm{CO})_{5}$. Also, the solid state of Fec requires an evaporator with larger surface areas for heat and mass transfer. Our evaporator design, based upon that of Megaridis [22], has a (30 \pm 5$) \mathrm{cm}^{3}$ packed bed (to provide the bulk of the ferrocene), followed by thirty sublimation stages (to insure that the carrier gas is saturated with $\mathrm{Fec}$ at the bath temperature). Each sublimation stage consists of a $5 \mathrm{~mm}$ layer of ferrocene on a $2.36 \mathrm{~cm}$ diameter 60 mesh stainless steel screen. A 4 mm gap separates each stage. The vapor pressure correlation of Pelino et al. [31] is used to determine the ferrocene mole fraction in the carrier gas. Temperature controllers maintain the transfer lines at $(80 \pm 3){ }^{\circ} \mathrm{C}$ and the burner tube at $(80 \pm 1){ }^{\circ} \mathrm{C}$. For all flames, the equivalence ratio (in the absence of inhibitor) is 1.0 , and agent mole fraction is calculated relative to the total 
reactant flow. The flows of fuel, oxidizer, Fec- $\mathrm{N}_{2}$, and the blended agent $\left(\mathrm{CO}_{2}\right.$, or $\left.\mathrm{CF}_{3} \mathrm{H}\right)$ are mixed after the Fec evaporator. The inlet reactant stream temperature is $(80 \pm 1){ }^{\circ} \mathrm{C}$, which corresponds to a calculated adiabatic flame temperature of $2260 \mathrm{~K}$ and $2391 \mathrm{~K}$ for uninhibited flames at $X_{O_{2}, o x}=0.21$ and 0.244 .

\subsubsection{Numerical modeling}

The laboratory flames inhibited by $\mathrm{Fec}$ and $\mathrm{Fec}-\mathrm{CO}_{2}$ blends were numerically modeled as onedimensional freely-propagating flames. Solutions were obtained using the Sandia flame code Premix [32], and the Chemkin [33] and transport property [34] subroutines. Details of the calculations are provided elsewhere [28]. Little is known about the chemical kinetic behavior of ferrocene in flames. A rate constant exists for its thermal decomposition: $k=2.188 \cdot 10^{16} \exp (-$ $384 \mathrm{~kJ} / \mathrm{RT}$ ) $\mathrm{s}^{-1}$ [35], but the activation energy is high, leading one to suspect that reactions with radicals may also be important. Thermodynamic data are available [36,37], and the transport properties are estimates [38,39]. A reaction set for combustion of methane and larger hydrocarbon fragments was adopted from Sung et al. [40]. We added iron chemistry from a mechanism developed for flame inhibition by $\mathrm{Fe}(\mathrm{CO})_{5}$ [5]. Overall, the kinetic model contains 105 species and 677 reactions. Calculations showed that addition of $\mathrm{C}_{5} \mathrm{H}_{5}$ at mole fractions up to $400 \mathrm{ppm}$ had negligible effect on the burning velocity, and that the major effect of Fec is from the iron chemistry. It should be emphasized that the reaction mechanism used for the present calculations should be considered only as a starting point. Numerous changes to both the rates and the reactions incorporated may be made once a variety of experimental and theoretical data are available for testing the mechanism.

\subsubsection{Results and Discussion}

\subsubsection{Inhibition by Ferrocene}

Figure 13 shows the relative burning velocity reduction with addition of Fec (open symbols) or $\mathrm{Fe}(\mathrm{CO})_{5}$ (closed symbols) to the present slightly pre-heated $\left(80{ }^{\circ} \mathrm{C}\right)$ methane-air flames. (The uncertainties in the experimental data, described in detail previously [41], are typically about $\pm 5 \%$.) Data are plotted as normalized burning velocity, which is the burning velocity of the inhibited flame divided by the value for the same flame in the absence of inhibitor. The uninhibited experimental burning velocities used for the normalizations are $(53.7 \pm 3) \mathrm{cm} / \mathrm{s}$ and $(75.9 \pm 6) \mathrm{cm} / \mathrm{s}$ for $X_{O_{2}, o x}=0.21$ and 0.244 respectively; for comparison, the calculations for uninhibited flames using GRI-Mech 1.2 yield $55.5 \mathrm{~cm} / \mathrm{s}$ and $72.6 \mathrm{~cm} / \mathrm{s}$. The effect of the two agents is essentially the same, with very strong initial inhibition followed by a loss of effectiveness above a few hundred ppm of agent, as found previously for $\mathrm{Fe}(\mathrm{CO})_{5}$ inhibition in flames with reactants at $21{ }^{\circ} \mathrm{C}$ [9].

Figure 13 shows that for both $\mathrm{Fec}$ and $\mathrm{Fe}(\mathrm{CO})_{5}$, the magnitude of the inhibition is strongly dependent upon the oxygen mole fraction in the oxidizer, with flames with lower mole fraction of $\mathrm{O}_{2}$ showing more rapid burning velocity reduction. As a result, blends of inert agents with iron-containing compounds may greatly increase the efficiency over that of the inert alone. 
The modeling results for the ferrocene-inhibited flames are also shown in Figure 13. The calculations (dotted lines) predict the flame speed reduction caused by ferrocene reasonably well. The major difference between the ferrocene reaction scheme and that for $\mathrm{Fe}(\mathrm{CO})_{5}$ is in the decomposition of the iron precursor. The present mechanism includes only the high-activation energy thermal decomposition step for Fec consumption: $\mathrm{FeC}_{10} \mathrm{H}_{10} \rightarrow \mathrm{Fe}+2 \mathrm{C}_{5} \mathrm{H}_{5}$, which has a peak reaction flux at $1800 \mathrm{~K}$ in the present flames. In contrast, iron pentacarbonyl decomposition has a peak reaction flux at about $900 \mathrm{~K}$. Figure 14 shows the normalized burning velocity for a methane-air flame with $400 \mathrm{ppm}$ of ferrocene as a function of the hypothetical activation energy $E_{a}$ of the one-step decomposition reaction. In the temperature range of the stoichiometric methane-air flame of the figure, the predicted inhibition effect of Fec is independent of the overall activation energy of the decomposition of Fec for values of $E_{a}$ less than about $400 \mathrm{~kJ} / \mathrm{mol}$. Hence, the decomposition rate of Fec used in the model $\left(\mathrm{E}_{\mathrm{a}}=384\right.$ $\mathrm{kJ} / \mathrm{mol}$ ) does not influence the predicted behavior. For other conditions, however, (for example non-preheated reactants and highly diluted flames) the decomposition of Fec may need to be modeled more accurately to provide agreement with experimental data.

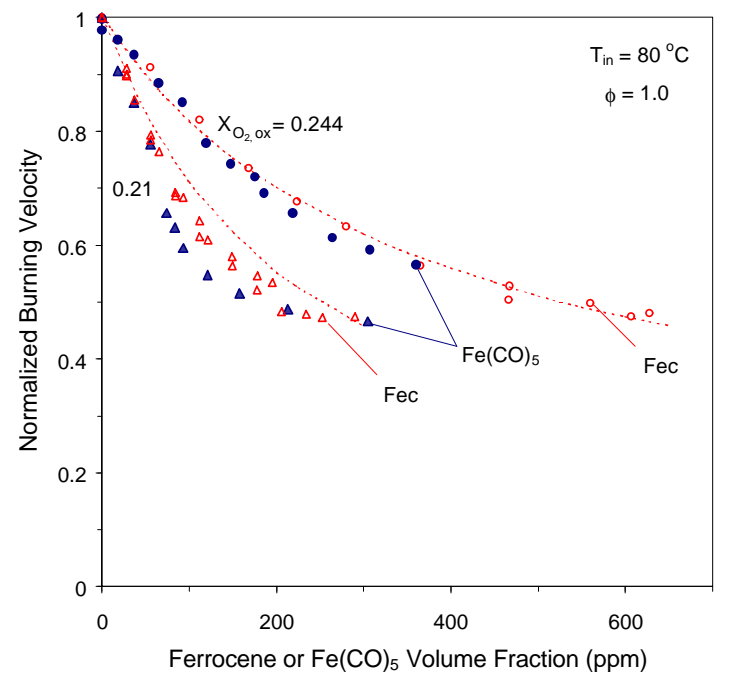

Figure 13 - Normalized burning velocity of premixed $\mathrm{CH}_{4} / \mathrm{O}_{2} / \mathrm{N}_{2}$ flames inhibited by ferrocene (open symbols) and $\mathrm{Fe}(\mathrm{CO})_{5}$ (closed symbols) for $X_{O 2, o x}=0.21$ and 0.244 , together with modeling predictions (dotted lines).

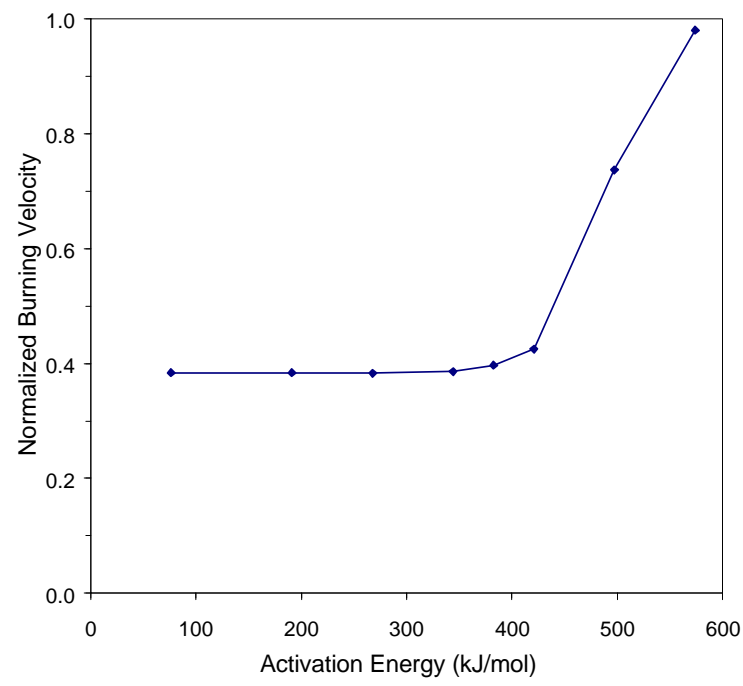

Figure 14 - The normalized burning velocity of stoichiometric $\mathrm{CH}_{4} / \mathrm{O}_{2} / \mathrm{N}_{2}$ flames at $400 \mathrm{ppm}$ of Fec as a function of the activation energy of the one-step ferrocene decomposition reaction.

Since both the $\mathrm{Fec}$ and $\mathrm{Fe}(\mathrm{CO})_{5}$ mechanisms use the same iron sub-mechanism, the mode of flame speed reduction in the model is the same. Decomposition of the ferrocene molecule releases iron atom in the gas phase. Iron reacts with $\mathrm{O}_{2}$ to form $\mathrm{FeO}_{2}$, which reacts with $\mathrm{O}$ atom to form $\mathrm{FeO}$. $\mathrm{FeO}$ is a long-lived intermediate, which together with $\mathrm{Fe}(\mathrm{OH})_{2}$ and $\mathrm{FeOH}$, enters into the catalytic cycle for $\mathrm{H}$-atom recombination

$$
\begin{gathered}
\mathrm{FeOH}+\mathrm{H} \leftrightarrow \mathrm{FeO}+\mathrm{H}_{2} \\
\mathrm{FeO}+\mathrm{H}_{2} \mathrm{O} \leftrightarrow \mathrm{Fe}(\mathrm{OH})_{2} \\
\mathrm{Fe}(\mathrm{OH})_{2}+\mathrm{H} \leftrightarrow \mathrm{FeOH}+\mathrm{H}_{2} \mathrm{O} \\
\text { (net: } \left.\mathrm{H}+\mathrm{H} \leftrightarrow \mathrm{H}_{2}\right) .
\end{gathered}
$$


The modeling results show that the stronger burning velocity reduction for the cooler flames $\left(X_{O_{2}, o x}=0.21\right)$ is due to their smaller radical pool; in these flames, a given amount of iron can remove a larger percentage of the hydrogen radicals.

Ferrocene appears to be an alternative to the highly toxic iron pentacarbonyl for addition of gasphase iron to a flame. Unfortunately, its effectiveness also appears to diminish as the mole fraction increases. For $\mathrm{Fe}(\mathrm{CO})_{5}$ the loss of effectiveness has been identified to be due to formation of condensed-phase particulates in the reaction zone [42]. Since addition of nitrogen clearly increases the rate of burning velocity reduction at low mole fraction (note the results in Figure 13 for $X_{O_{2}, o x}=0.21$ and 0.244 ), it is of interest to determine if other thermally acting agents can be combined with Fec to mitigate the loss of effectiveness, and perhaps enhance the flame speed reduction at low Fec mole fraction. It is desired to take advantage of the strong initial flame speed reduction from iron species in the flame, while avoiding the loss of active species due to condensation. A drawback, however, is that addition of an inert, while reducing the burning velocity, also increases the residence time for particle formation in the flame, so that condensation is increased [42]. It is not known a priori if the net effect of combining thermal and iron-containing agents will reduce the overall reaction rate faster than the increase of the rate of active-species condensation.

\subsubsection{Inhibition by Ferrocene and $\mathrm{CO}_{2}$}

Figure 15a and Figure 15b present the experimental data for tests at $X_{O_{2}, o x}=0.21$ and 0.244. Data are shown for pure $\mathrm{CO}_{2}$ as well as for $\mathrm{CO}_{2}-\mathrm{Fec}$ blends corresponding to three values of the mole percentage of $\mathrm{Fec}$ in $\mathrm{CO}_{2}(0 \%, 0.25 \%$, and $1.5 \%$ in Figure 15a, and $0 \%, 0.4 \%$, and $1.5 \%$ in Figure 15b). For the pure compounds, addition of about $10 \%$ of $\mathrm{CO}_{2}$ (or $25 \% \mathrm{~N}_{2}$ ) reduces $\mathrm{S}_{\mathrm{L}}$ by a factor of two at $X_{O_{2}, o x}=0.21$ or 0.244 . Adding $\mathrm{Fec}$ to $\mathrm{CO}_{2}$ produces a particularly effective agent. The equivalent of $0.35 \% \mathrm{Fec}$ in $\mathrm{CO}_{2}$ reduces the required $\mathrm{CO}_{2}$ for a $50 \%$ reduction in the flame speed by about a factor of three at $X_{O_{2}, 0 x}=0.21$ and about a factor of two at $X_{O_{2}, o x}=0.244$. The combination of $1.5 \% \mathrm{Fec}$ reduces the required $\mathrm{CO}_{2}$ by ten, making this blend about as effective as $\mathrm{CF}_{3} \mathrm{Br}$ (for which addition of about $1 \%$ halves the burning velocity). Nonetheless, the curvature in the ends of the data sets (particularly for $1.5 \% \mathrm{Fec}$ in $\mathrm{CO}_{2}$ ) illustrates condensation can be important. Although one might expect the slightly cooler, slower flames with added $\mathrm{CO}_{2}$ to always show more condensation of iron species, the greater efficiency of the catalytic cycle in the diluted flames predominates for most of the conditions for the flame of Figure 15. Higher effectiveness of iron compounds in diluted flames has been observed previously for flames with $X_{O_{2}, o x}$ lowered below 0.21 [9]. 

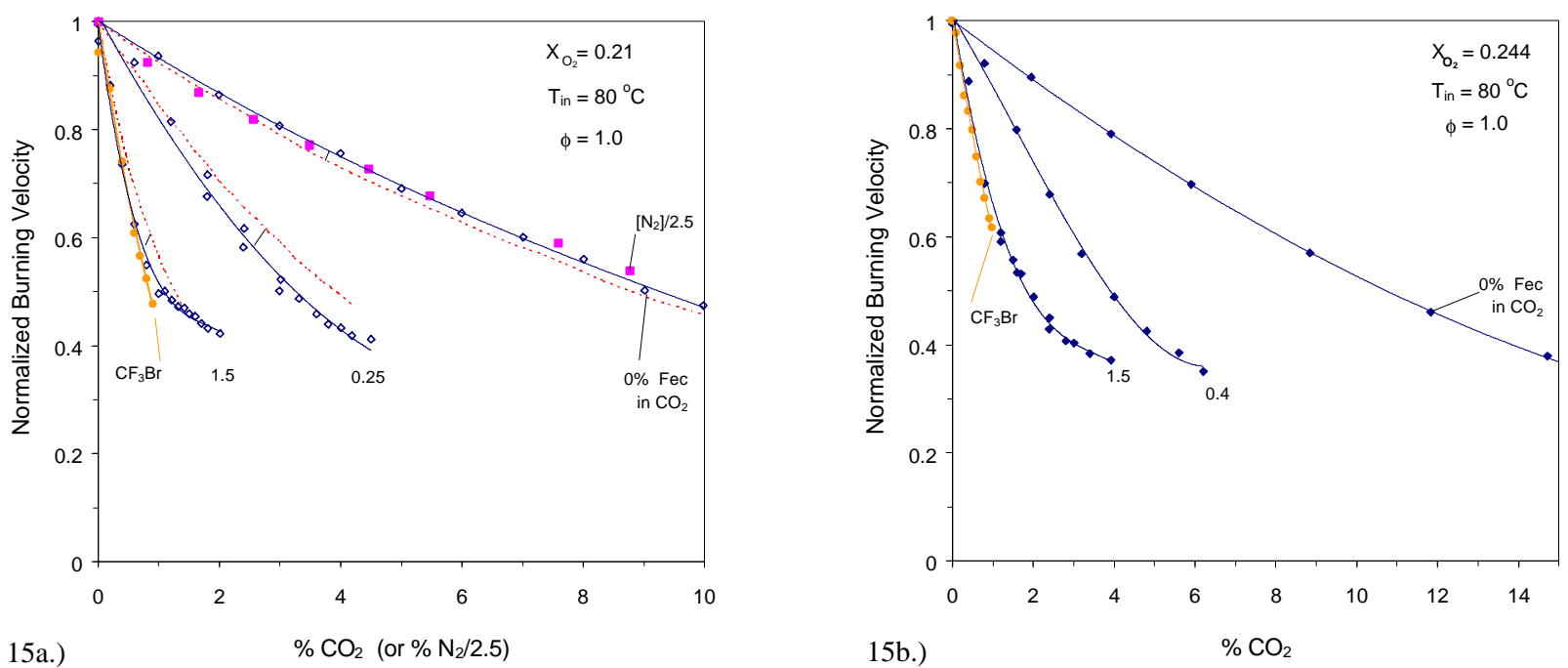

Figure 15 - Normalized burning velocity of $\mathrm{CH}_{4} / \mathrm{O}_{2} / \mathrm{N}_{2}$ flames, a) $X_{O_{2}, o x}=0.21$, b) $X_{O_{2}, o x}=0.244$, inhibited by $\mathrm{CO}_{2}$, by $\mathrm{CO}_{2}$-ferrocene blends, and by $\mathrm{CF}_{3} \mathrm{Br}$. The equivalent percentage of ferrocene in $\mathrm{CO}_{2}$ (which is constant for each curve) is given. The solid lines are curve fits through the data, and the dotted lines, the calculated results. Data for nitrogen are included in a.) by dividing $\% \mathrm{~N}_{2}$ by 2.5 .

The condensation behavior of the blends can be discerned from Figure 16a and 7b, which present additional data for $\mathrm{CO}_{2}$ and ferrocene in stoichiometric flames with $X_{O_{2}, o x}=0.21$ and 0.244 , respectively. In Figure $15, \mathrm{CO}_{2}$ and ferrocene were added together in proportional amounts, whereas in Figure 16, $\mathrm{CO}_{2}$ is first added at a constant volume fraction $(0 \%, 2 \%$, and $6 \%$ in $7 \mathrm{a}$; or $0 \%, 4 \%$, and $12 \%$ in $7 \mathrm{~b}$ ), and then the Fec is added. This approach allows a clearer delineation of the effects of each component of the blend. As the figures show, the curve with $0 \% \mathrm{CO}_{2}$ (pure $\mathrm{Fec}$ ) has a decreasing slope magnitude as $X_{\text {in }}$ increases (due to increased condensation). For each of the other curves, the added $\mathrm{CO}_{2}$ reduces the normalized burning velocity before the Fec is added, so that each curve starts at a value less than unity; addition of Fec further reduces the flame speed. Below an Fec volume fraction of about $70 \mathrm{ppm}$, the curves are all quite linear, showing that there no loss of effectiveness. But for curves extending beyond this amount of Fec, there is increasing curvature as $X_{i n}$ increases (due to condensation). Nonetheless, at low mole fractions, the inhibition by Fec is actually stronger for conditions of higher $\mathrm{CO}_{2}$ mole fraction (note the larger magnitude of the slope for the $12 \% \mathrm{CO}_{2}$ curve in Figure 16b). Hence, for some conditions, adding $\mathrm{CO}_{2}$ makes $\mathrm{Fec}$ more effective. As discussed below, once the particles start to form, the deterioration of inhibition may be more rapid with added $\mathrm{CO}_{2}$. These results imply that combinations of non-condensing quantities of several catalytic agents combined with a thermal agent can be particularly effective. 

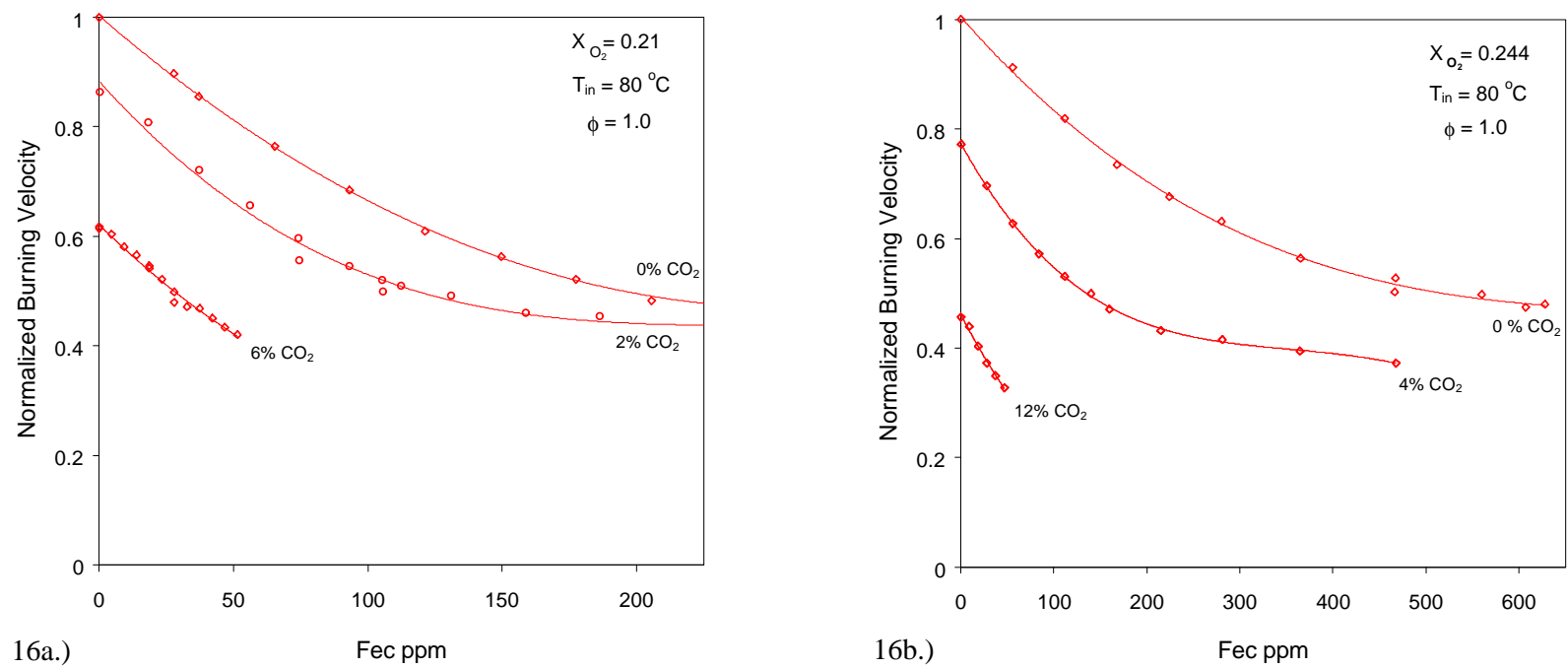

Figure 16 - Normalized burning velocity of $\mathrm{CH}_{4} / \mathrm{N}_{2} / \mathrm{O}_{2}$ flames, a.) $X_{O_{2}, o x}=0.21$, b.) $X_{O_{2}, 0 x}=0.244$, with 0,2 , and 6, or 0,6 , and 12 volume percent of $\mathrm{CO}_{2}$, respectively, added to the reactant stream, as a function of added ferrocene (lines are curve fits to the experimental data).

\subsubsection{Inhibition by Ferrocene and $\mathrm{CF}_{3} \mathrm{H}$}

Many compounds are candidates for blending with catalytic agents, including thermally acting and other chemical agents. Hydrofluorocarbons, which are easily stored at moderate pressure, are of interest since they are presently used as halon replacements. These compounds have been found to reduce the burning velocity of premixed methane-air flames by reducing peak $\mathrm{H}$-atom mole fractions by acting as a sink for $\mathrm{H}$ atoms through reactions forming $\mathrm{HF}$, and by lowering the temperature of the flame. Since they have also been shown to reduce the equilibrium mole fractions of radicals in flames lower than expected based on temperature reduction alone [43], they might be expected to show enhanced performance relative to $\mathrm{CO}_{2}$ when combined with catalytic agents.

Figure 17 presents the burning velocity reduction caused by pure $\mathrm{CF}_{3} \mathrm{H}$ addition to the above flames; a mole fraction of about $5 \%$ is required to reduce $\mathrm{S}_{\mathrm{L}}$ by two. Data are also presented for addition of $0.35 \% \mathrm{Fec}$ in $\mathrm{CF}_{3} \mathrm{H}$. Unlike ferrocene addition to $\mathrm{CO}_{2}$, in which $0.35 \% \mathrm{Fec}$ in $\mathrm{CO}_{2}$ reduces the amount of $\mathrm{CO}_{2}$ required by a factor of about five, this amount of ferrocene in $\mathrm{CF}_{3} \mathrm{H}$ reduces the amount of $\mathrm{CF}_{3} \mathrm{H}$ required only by about a third. This poor performance may be due to reactions between iron species and fluorine, which reduce the gas-phase mole fraction of the active iron-species intermediates, effectively poisoning the iron catalyst [44]. 


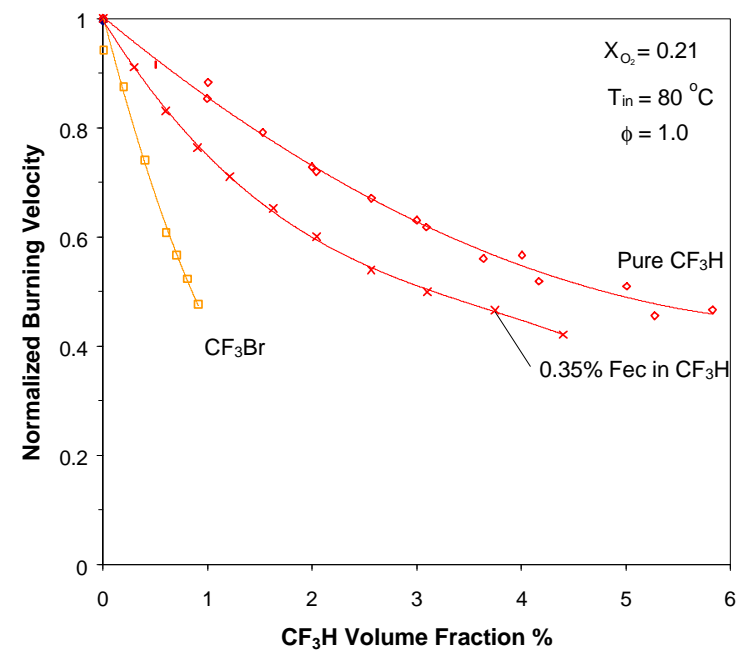

Figure 17 - Normalized burning velocity of premixed $\mathrm{CH}_{4} / \mathrm{O}_{2} / \mathrm{N}_{2}$ flames inhibited by pure $\mathrm{CF}_{3} \mathrm{H}$ and by $\mathrm{CF}_{3} \mathrm{H}$ with $0.35 \%$ ferrocene, together with data for $\mathrm{CF}_{3} \mathrm{Br}$. Lines are curve fits to the data.

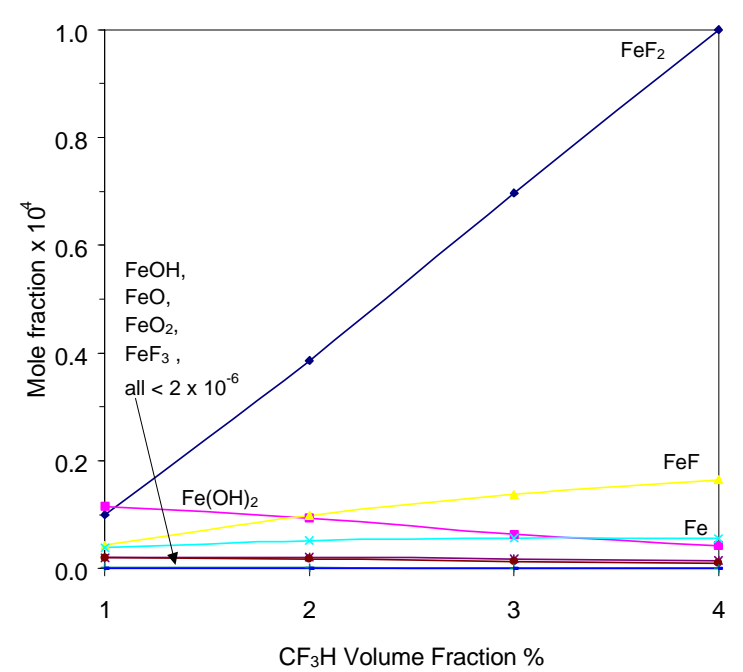

Figure 18 - Equilibrium mole fraction of active inhibiting species $\left(\mathrm{Fe}, \mathrm{FeO}, \mathrm{FeOH}, \mathrm{Fe}(\mathrm{OH})_{2}\right.$ ) and iron-fluorine species with $1 \%$ to $4 \% \mathbf{C F}_{3} \mathrm{H}$ (containing $0.35 \%$ ferrocene) added to a stoichiometric methane-air reaction mixture.

Since there presently exist no experimental data on the rates of reactions of iron species with fluorine containing species in flames, the poisoning effect of fluorinated hydrocarbons on ironcatalyzed radical recombination reactions is assessed through equilibrium calculations for the combustion products. The species included in the calculations are those in the mechanisms for hydrocarbon oxidation, iron-inhibition, and fluorinated hydrocarbon-inhibition [45], as well as the iron-fluorine species: $\mathrm{FeF}, \mathrm{FeF}_{2}, \mathrm{FeF}_{3}, \mathrm{Fe}_{2} \mathrm{~F}_{4}, \mathrm{Fe}_{2} \mathrm{~F}_{6}$ [46]. Calculations were performed for the equilibrium products of a stoichiometric methane-air flame with $1 \%$ to $4 \% \mathrm{CF}_{3} \mathrm{H}$ containing $0.35 \% \mathrm{Fec}$ (the conditions of Figure 17). The results of the calculations, shown in Figure 18, indicate that $\mathrm{FeF}$ and $\mathrm{FeF}_{2}$ are major product species when $\mathrm{CF}_{3} \mathrm{H}$ has been added. For $1 \%$ to $4 \% \mathrm{CF}_{3} \mathrm{H}$, the amount of iron taken up by the sum of $\mathrm{FeF}$ and $\mathrm{FeF}_{2}$ increases from $42 \%$ to $84 \%$, making less iron available in the form of the active iron intermediate species $\mathrm{Fe}, \mathrm{FeO}, \mathrm{FeOH}$, $\mathrm{FeO}_{2}$, and $\mathrm{Fe}(\mathrm{OH})_{2}$. The formation of fluorinated iron species with strong bonds can clearly act as a sink for iron in the flame, and reduce the mole fractions of active iron-containing species available to participate in the flame inhibition reactions. While the experiments and calculations are presented for $\mathrm{CF}_{3} \mathrm{H}$, the results are likely to be the similar for larger $\mathrm{HFCs}$ such as $\mathrm{C}_{2} \mathrm{HF}_{5}$ and $\mathrm{C}_{3} \mathrm{HF}_{7}$ since the decomposition of all proceeds largely through the $\mathrm{CF}_{3}, \mathrm{CF}_{2}$, and $\mathrm{CFO}$ intermediates $[30,43,47]$. 


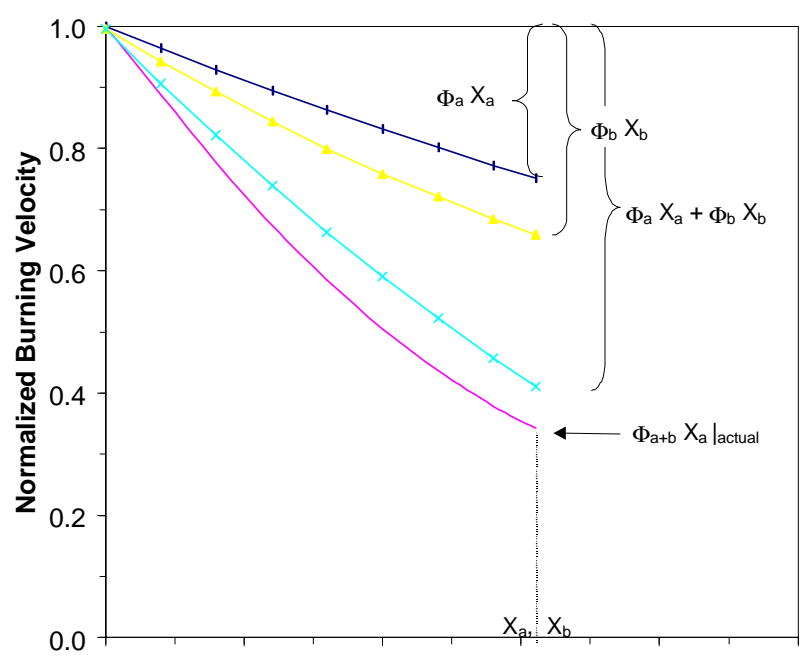

Inhibitor(s) Mole Fraction

Figure 19 - Illustration of linear contribution of burning velocity reduction from each component of a two-component blend of inhibitors, together with the actual reduction from the blend.

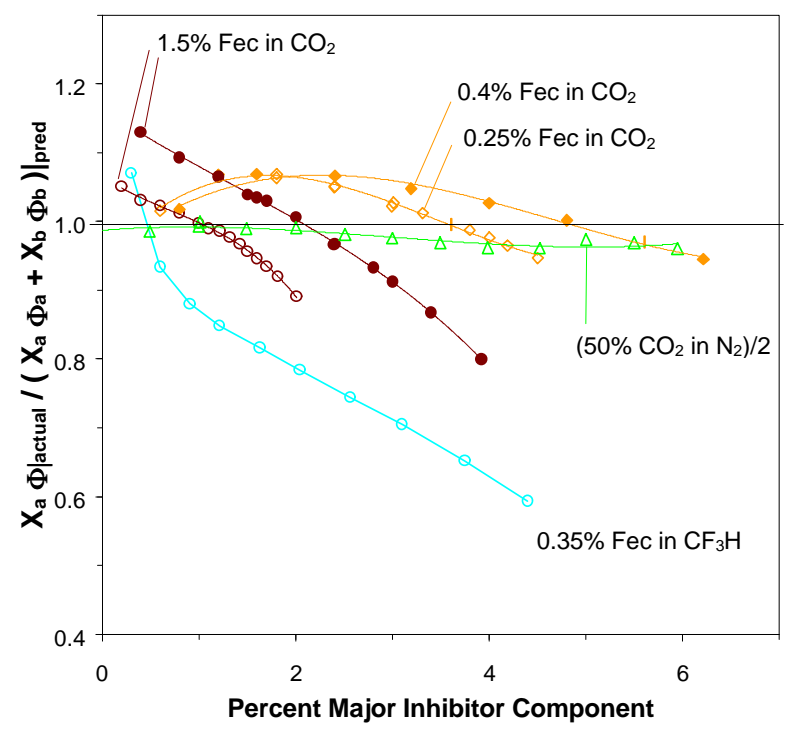

Figure 20 - Ratio of the actual reduction in $S_{L}$ from the two component mix to the predicted reduction based on linear combination of the effect from each component. Open and closed symbols are for $X_{O_{2}, o x}=0.21$ and 0.244 ; lines are curve fits to the data. The percent $\mathrm{CO}_{2} / \mathrm{N}_{2}$ has been divided by two to fit on the figure.

\subsubsection{Comparison of Individual and Blended Performance}

The behavior of the blends of agents can be investigated by comparing the actual amount of flame speed reduction for the blend to the sum of the inhibition which would result from each agent individually. This approach is illustrated schematically in Figure 19. We adopt the inhibition index $\Phi\left(X_{\text {in }}\right)$ of Fristrom and Sawyer [48], where $\Phi\left(X_{\text {in }}\right)=\left\{\left\{\left(\mathrm{V}_{\mathrm{o}}-\mathrm{V}\left(X_{\text {in }}\right.\right.\right.\right.$ )) $\left./ \mathrm{V}_{\mathrm{o}}\right\}\left\{X_{O_{2}, o x} / X_{\text {in }}\right\}$ (and using the oxygen mole fraction in the oxidizer). The index $\Phi\left(X_{i n}\right)$ is seen to be the magnitude of the average slope of the normalized burning velocity curve (times $X_{O_{2}, o x}$ ) evaluated at the mole fraction of interest $X_{i n}$. For a given blend, we can evaluate the amount of normalized burning velocity reduction that would have been caused by each individual component of the blend, say components $a$ and $b$. The predicted inhibition index is just a linear combination of the reduction from each component, or $\left.X_{a} \cdot \Phi_{\mathrm{a}+\mathrm{b}}\left(X_{a}, X_{b}\right)\right|_{\text {pred }}=X_{a}$. $\Phi_{\mathrm{a}}\left(X_{a}\right)+X_{a} \cdot \Phi_{\mathrm{b}}\left(X_{b}\right)$, in which $a$ is the major component of the blend, (and we have selected it for defining $\left.\Phi_{\mathrm{a}+\mathrm{b}}\left(X_{a}, X_{b}\right)\right)$. The actual inhibition index $\left.\Phi_{\mathrm{a}+\mathrm{b}}\left(X_{a}, X_{b}\right)\right|_{\text {actual }}$ is evaluated from the normalized flame speed of the blend (using $X_{a}$ in its definition). The ratio of $\left.X_{a} \cdot \Phi_{\mathrm{a}+\mathrm{b}}\left(X_{a}, X_{b}\right)\right|_{\text {actual }}$ to $X_{a} \cdot \Phi_{\mathrm{a}}\left(X_{a}\right)+X_{a} \cdot \Phi_{\mathrm{b}}\left(X_{b}\right)$ provides a reasonable indicator of the performance of the blend relative to the individual components.

As Figure 20 shows, a blend of $\mathrm{CO}_{2}$ and $\mathrm{N}_{2}$ (in the molar ratio of 1:2) provides a performance index of nearly 1.0 for $\mathrm{N}_{2}$ added up to $12 \%$ (i.e., containing $6 \% \mathrm{CO}_{2}$ ). (The percent amount of the $\mathrm{N}_{2} / \mathrm{CO}_{2}$ mix plotted in Figure 20 is divided by two to allow plotting on the same scale.) In 
contrast, the poor performance of the $\mathrm{Fec}_{-} \mathrm{CF}_{3} \mathrm{H}$ blend is clearly indicated by a decreasing performance index as $X_{i n}$ increases. For the $\mathrm{CO}_{2} / \mathrm{Fec}$ blends, the combination appears to work slightly better than the individual components at low $X_{\text {in }}$ of the blend, and slightly worse at higher $X_{i n}$. The good performance at low $X_{i n}$ is due to the higher radical super-equilibrium which occurs with flame dilution as observed previously for $\mathrm{N}_{2}$ addition [9], and the degraded performance at higher $X_{i n}$ is due to the longer residence times for condensation which result from the lower flame speeds [42]. In Figure 20, the condition at which the curves for $\mathrm{Fec} / \mathrm{CO}_{2}$ crossover the unity ratio correspond roughly to the location on the curves in Figure 15, where the linear behavior has ended and the curvature begins.

\subsubsection{Conclusions}

This section presents the first data on flame inhibition by ferrocene, and shows it to be as efficient as $\mathrm{Fe}(\mathrm{CO})_{5}$ at reducing the burning velocity of premixed methane flames. Ferrocene, like $\mathrm{Fe}(\mathrm{CO})_{5}$, loses its effectiveness at a mole fraction above a few hundred ppm. The experimental results are reasonably predicted by a gas-phase iron inhibition mechanism. The results imply that any rapidly decomposing iron-containing agent that releases atomic iron in the gas phase can act as a precursor for the active iron-species intermediates, and that the results are not unique to $\mathrm{Fe}(\mathrm{CO})_{5}$. As with $\mathrm{Fe}(\mathrm{CO})_{5}$, the magnitude of the inhibition by ferrocene has a strong dependence on the oxygen mole fraction. As a result, many combinations of $\mathrm{CO}_{2}$ and $\mathrm{Fec}$ show strong inhibition, mitigating the loss of effectiveness observed for pure $\mathrm{Fec}$ or $\mathrm{Fe}(\mathrm{CO})_{5}$. The results imply that an inert agent, together with multiple catalytic agents (to keep the absolute mole fraction of each below the saturation point) may prove to be highly effective for all conditions. In contrast to the results with $\mathrm{CO}_{2}$, blends of $\mathrm{CF}_{3} \mathrm{H}$ and Fec are not particularly effective, implying that iron species and halogens may enter into undesired reactions which poison the catalytic cycles. These results with ferrocene imply that combinations of catalytically and relatively inert thermally acting inhibitors may prove to be an efficient approach for developing effective fire suppressants. A main conclusion of this section is that iron, in forms other than $\mathrm{Fe}(\mathrm{CO})_{5}$, acts as a very powerful flame inhibitor, and other means for introducing it to premixed flames should prove effective.

\subsection{Cup Burner Flame Extinction Tests with Super-Effective Chemical Inhibitors}

\subsubsection{Introduction}

The effectiveness of the iron compounds $\mathrm{Fe}(\mathrm{CO})_{5}$ and ferrocene $\left(\left(\mathrm{C}_{5} \mathrm{H}_{5}\right)_{2} \mathrm{Fe}\right.$, Fec $)$ has been observed in premixed Bunsen-type flames as well as in counterflow diffusion flames $[2,4,6,28,49]$. No tests with these agents, however, have been done in flames more typical of fires. The present work remedies this deficiency by presenting results for addition of these highly effective agents to cup-burner flames. Not only does the structure of cup burner flames resemble that of fires, but there also exists a large database of previous cup-burner extinction results for comparison with the present data. 


\subsubsection{Background}

One approach to overcoming the loss of effectiveness is to combine catalytic agents with inert agents; this is, the overall reaction rate is lowered in part by radical recombination by the catalytic agent, and in part by the lower temperature from the added diluent. This approach has been discussed in work since the 1950's [10,50-54], which suggested that combinations of thermally acting and catalytic agents might prove beneficial. These predictions have been confirmed in premixed flames with ferrocene and $\mathrm{CO}_{2}$ as the inhibitors [28,49] and in premixed and counterflow diffusion flames inhibited by $\mathrm{Fe}(\mathrm{CO})_{5}$ at reduced oxygen mole fraction in the oxidizer (which is equivalent to adding diluent nitrogen) [6]. Moreover, previous tests with $\mathrm{Fe}(\mathrm{CO})_{5}$ at reduced oxygen mole fraction, and tests with ferrocene blended with $\mathrm{CO}_{2}$, show that addition of an inert compound can actually enhance the performance of the catalytic agent. Nonetheless, it is generally not known a priori if the combination of an inert with the catalytic agents will be effective in a particular flame configuration: the lower oxygen mole fraction (or added diluent) makes the catalytic effect stronger, while the lower temperature (and consequently longer residence in premixed flames) increases the likelihood of condensation [9].

Motivated by these results, tests of ferrocene together with an inert compound generated by a solid propellant gas generator (SPGG) have recently been conducted in an enclosure containing a spray flame [55]. Unfortunately, the combination did not have the intended high efficiency, and failed to extinguish the flame. As described above, the combination of inert and catalytic agents has been shown to be effective in premixed flames and counterflow diffusion flames. Notwithstanding, carefully controlled tests like those in the premixed and counterflow diffusion flames have not been performed in cup-burner flames. In order to explore possible reasons for the lack of effectiveness of Fec with the SPGG in suppressing the spray flame tested, we performed tests with catalytic metal-based inhibitors and $\mathrm{CO}_{2}$ added to a cup burner.

Extrapolating from our recently acquired understanding of the action of iron in premixed and diffusion flames, addition of $\mathrm{Fe}(\mathrm{CO})_{5}$ alone to the air stream of a cup burner would not be expected to be efficient at extinguishing the flame. This is because particle formation acts as a sink for the active gas-phase inhibiting species, keeping the maximum inhibiting species mole fractions at their saturation value. That is, adding more and more $\mathrm{Fe}(\mathrm{CO})_{5}$ to the air stream does not increase the gas-phase mole fraction of active inhibiting species, so we may never be able to extinguish a cup-burner flame (or a spray flame) with $\mathrm{Fe}(\mathrm{CO})_{5}$ or $\mathrm{Fec}$ alone. However, based on the premixed results with $\mathrm{Fec}$ and $\mathrm{CO}_{2}$, we would expect that added Fec (or $\mathrm{Fe}(\mathrm{CO})_{5}$ ) should significantly reduce the amount of $\mathrm{CO}_{2}$ necessary to extinguish the cup-burner flame. This approach should be effective for two reasons. First, based on premixed flame results presented previously, we expect that adding 200 ppm or above of iron should reduce the overall reaction rate by about a factor of four (i.e., about a factor of two reduction in flame speed); and second, with added inert the effectiveness of the iron in the gas phase should be improved. Hence, we would expect that adding an effective catalytic agent to the air stream would reduce the amount of $\mathrm{CO}_{2}$ required to extinguish the flame.

Two approaches are used in the present work. In the first, the catalytic agent $\mathrm{Fe}(\mathrm{CO})_{5}$ is added to the co-flowing air or fuel stream at two mole fractions, and the amount of added $\mathrm{CO}_{2}$ required to extinguish the flame is determined. In the second approach, the fuel consumption rate of the burner (due to heat feedback from the flame) is measured in the presence of increasing amounts 
of $\mathrm{CO}_{2}$, with and without added $\mathrm{Fe}(\mathrm{CO})_{5}$ in the air stream. An effective fire suppressant would be expected to reduce the fuel consumption rate, much as do fire retardants added to materials. We present some data for extinction of cup-burner flames of heptane and methanol, but most of the extinction tests were performed in flames of methane. Tests with flames of methane are warranted since they have been shown to provide similar inhibitor rankings for extinction compared to other larger hydrocarbon fuels [56]. Also, although methane oxidation is atypical of that of larger hydrocarbons, Babushok and Tsang have recently observed [29] that for a wide variety of hydrocarbons (including methane) the burning velocity is most sensitive to the rates of the same reactions. Since these reactions are the ones most influenced by an inhibitor, the trends in inhibitor effectiveness are the same for most hydrocarbons.

\subsubsection{Experiment}

A cup burner [57,58] was used for the tests. The cylindrical borosilicate glass cup, $28 \mathrm{~mm}$ in outside diameter with a $45^{\circ}$ bevel on the inside edge was positioned with the top at a height of $20.5 \mathrm{~cm}$ inside a $53.3 \mathrm{~cm}$ tall, $9.5 \mathrm{~cm}$ inside diameter glass chimney. A $7.5 \mathrm{~cm}$ thick bed of glass beads ( $6 \mathrm{~mm} \mathrm{dia})$ at the base of the chimney provided uniform laminar flow in the air stream. The cup burner was operated with methane, methanol, or heptane fuel. For the methane tests, the fuel cup was filled with $3 \mathrm{~mm}$ dia. glass beads, with two $15.8 \mathrm{mesh} / \mathrm{cm}$ stainless steel screens (separated by $1 \mathrm{~mm}$ ) at the top. For the liquid fuels, a dual syringe-pump (Yale Apparatus model YA-12) feed system provided fuel at measured rates. In the first tests, the fuel consumption rate of the burner was determined by adjusting the syringe pumping rate such that the fuel level was flush at the edge of the burner. This approach, while apparently working well, was time consuming since it required long wait periods (several minutes) between changes in the feed rate to insure that the fuel level remained at a constant level at the burner rim. A subsequent method used an overflow system as in ref. [58]. Gas flows were measured with digitally-controlled mass flow controllers (Sierra 860) with a quoted repeatability of $0.2 \%$ and accuracy of $1 \%$ of fullscale flow, which have been calibrated with bubble (Gillian Gilibrator), piston (Bios 20K), and dry (American Meter Co. DTM-200A) flow meters so that their accuracy is $2 \%$ of indicated flow.

The organometallic inhibitor $\mathrm{Fe}(\mathrm{CO})_{5}$ was added to the air stream using a two-stage saturator in a controlled temperature bath. The $\mathrm{Fe}(\mathrm{CO})_{5}$ was added at mole fractions up to $950 \mathrm{ppm}$ using the saturator described previously [10]. The mole fraction of the $\mathrm{Fe}(\mathrm{CO})_{5}$ inhibitor in the air stream was calculated based on the measured air flow, measured carrier gas flow $\left(\mathrm{N}_{2}\right.$ or $\left.\mathrm{CH}_{4}\right)$, and the calculated vapor pressure of the agent at the bath temperature, assuming saturated carrier gas (which has been verified in previous work). The Antoine equation for $\mathrm{Fe}(\mathrm{CO})_{5}$ is $\log _{10}(\mathrm{P})=$ 6.77273-4.0932/(T+7.2283) [59].

To determine the extinction condition for pure $\mathrm{CO}_{2}$, the $\mathrm{CO}_{2}$ was added to the airflow in increasing amounts (with increments of $<1 \%$ ) until lift-off was observed. The test was repeated at least three times. In the presence of a second inhibitor, that agent was first added to the air stream at a constant mole fraction, and then the amount of added $\mathrm{CO}_{2}$ required for lift-off was determined as in the pure $\mathrm{CO}_{2}$ case. The amount of $\mathrm{CO}_{2}$ required for lift-off is reported as its mole fraction in the burner co-flow stream (i.e., the sum of the air, added $\mathrm{CO}_{2}$, and carrier-gas $\mathrm{CO}_{2}$ ). (Note that in some early tests, to be described in Table 2, $\mathrm{N}_{2}$ was used as the carrier gas 
instead of $\mathrm{CO}_{2}$. In those cases, we included the $\mathrm{N}_{2}$ in the $\mathrm{CO}_{2}$ flow by correcting for differences in specific heat between the two.) The fuel gas is methane (Matheson UHP, $99.9 \%$ ), and the oxidizer is house compressed air (filtered and dried) which is additionally cleaned by passing it through an $0.01 \mu \mathrm{m}$ filter, a carbon filter, and a desiccant bed to remove small aerosols, organic vapors, and water vapor. The chemicals used were $\mathrm{Fe}(\mathrm{CO})_{5}$ (Aldrich), TMT (Alfa Aesar), MMT (Alfa Aesar), $\mathrm{CH}_{3} \mathrm{OH}$ (Aldrich, $99.8 \%$ ), $\mathrm{Br}_{2}$ (Aldrich, $99.5 \%$ ), $\mathrm{CF}_{3} \mathrm{Br}$ (Great Lakes), $\mathrm{N}_{2}$ (boiloff), and $\mathrm{CO}_{2}$ (Airgas). The expanded relative uncertainties for the experimentally determined quantities in this study are $4 \%$ for the $\mathrm{CO}_{2}$ mole fraction, $5 \%$ for the $\mathrm{Fe}(\mathrm{CO})_{5}$ mole fraction, and otherwise as noted on the figures.

\subsubsection{Results and Discussion}

\subsubsection{Heptane - Air Flames}

We conducted our first tests in a heptane-fueled cup burner. In the absence of $\mathrm{Fe}(\mathrm{CO})_{5}$, the extinction condition occurs at a $\mathrm{CO}_{2}$ mole fraction of $(19.2 \pm 0.8) \%$. The value is somewhat low compared to other values in the literature, due to the low air volumetric flow, $25 \mathrm{~L} / \mathrm{min}$, in these tests. With about $450 \mathrm{ppm}$ of $\mathrm{Fe}(\mathrm{CO})_{5}$ added to the air stream, the amount of added $\mathrm{CO}_{2}$ required for extinction is reduced by only about $5 \%$. This result is unexpected since adding 150 ppm of $\mathrm{Fe}(\mathrm{CO})_{5}$ to a premixed methane-air flame reduces by a factor of eight the amount of $\mathrm{CO}_{2}$ required to halve the burning velocity.

For a cup burner flame, addition of $\mathrm{Fe}(\mathrm{CO})_{5}$ or $\mathrm{CO}_{2}$ might not only change the extinction condition, but might also change the heat release rate at each agent mole fraction. We measured the fuel consumption rate as an approximate measure of the heat release in the flame.

Figure 21 shows the heptane consumption rate in a cup burner as a function of the $\mathrm{CO}_{2}$ mole fraction in the air stream. The upper curve shows the results for pure $\mathrm{CO}_{2}$, while the lower curve presents the results for addition of $450 \mathrm{ppm}$ of $\mathrm{Fe}(\mathrm{CO})_{5}$ to the air stream prior to addition of $\mathrm{CO}_{2}$ to the air stream. As the figure shows, the presence of $\mathrm{Fe}(\mathrm{CO})_{5}$ causes a $16 \%$ to $38 \%$ reduction in the fuel consumption rate for $\mathrm{CO}_{2}$ mole fractions up to $75 \%$ of extinction; however, as described above for methane, the extinction condition changes by only about $5 \%$ with iron present. 


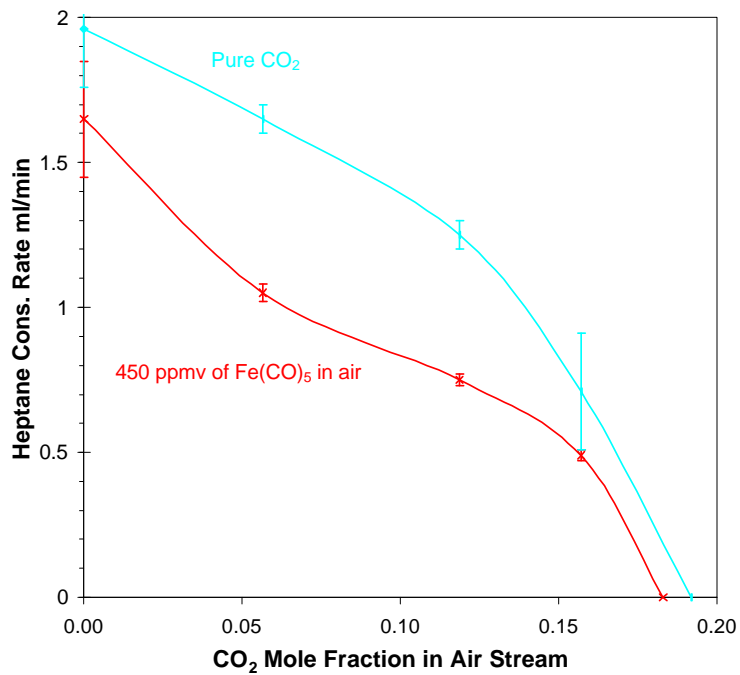

Figure 21 - Heptane consumption rate in cupburner flame as a function of added $\mathrm{CO}_{2}$ mole fraction with and without $450 \mathrm{ppm} \mathrm{Fe}(\mathrm{CO})_{5}$ added to the air stream

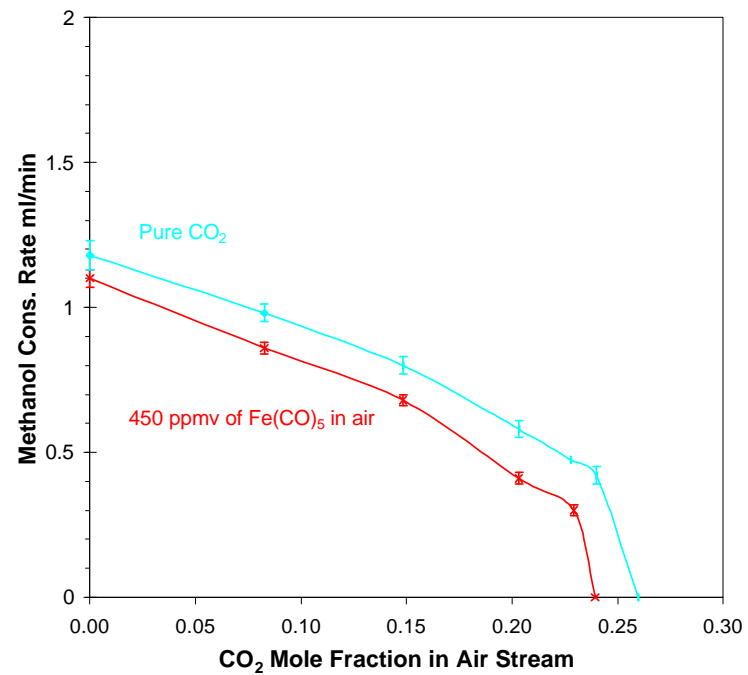

Figure 22 - Methanol consumption rate in cupburner flame as a function of added $\mathrm{CO}_{2}$ mole fraction with and without $450 \mathrm{ppm} \mathrm{Fe}(\mathrm{CO})_{5}$ added to the air stream.

Unfortunately, the results in Figure 21 are confounded by the sooting tendencies of heptane cupburner flames. Heat transfer to the pool surface is enhanced by soot in the gas phase, as well as by soot on the hot chimney walls. With addition of $\mathrm{Fe}(\mathrm{CO})_{5}$, soot production was visually observed to be reduced, which is consistent with its known effects on the sooting tendencies of flames [21-26]. (At higher mole fractions of added $\mathrm{CO}_{2}$, soot formation is visually observed to

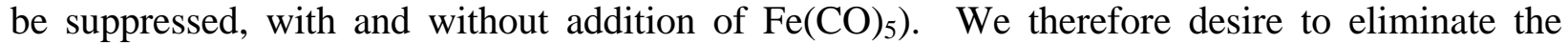
complicating effects of soot formation in cup-burner flames.

\subsubsection{Methanol - Air Flames}

In order to retain a liquid fuel but virtually eliminate sooting, we ran additional tests with methanol as the fuel. Tests were conducted to determine the amount of $\mathrm{CO}_{2}$ required for extinction with and without addition of $450 \mathrm{ppm}$ of $\mathrm{Fe}(\mathrm{CO})_{5}$ to the air stream. As with heptane, the reduction in $\mathrm{CO}_{2}$ required for extinction is small, here only about $8 \%$. Tests for the effect of air-stream addition of $\mathrm{Fe}(\mathrm{CO})_{5}$ on the methanol consumption rate were also conducted. Figure 22 shows the change in the methanol consumption rate with addition of $450 \mathrm{ppm}$ of $\mathrm{Fe}(\mathrm{CO})_{5}$ to the air stream, as a function of the amount of added $\mathrm{CO}_{2}$. We see that without the confounding effects of soot formation, the fuel consumption rate is reduced by a nearly constant amount. The fuel consumption rate is reduced somewhat, but the reduction is not nearly as high as might be expected based the overall reaction rate reduction in premixed methane-air flames. 


\subsubsection{Methane - Air Flames}

To further understand the influence of iron in cup-burner flames, we also conducted tests with methane fuel. In these tests, $\mathrm{Fe}(\mathrm{CO})_{5}$ could be added to either the fuel or the air stream, removing the uncertainty associated with agent transport to the relevant reaction zone. Table 2 summarizes the results for all of the tests. The top two entries show that addition of $\mathrm{Fe}(\mathrm{CO})_{5}$ to the air stream at quite high mole fractions (450 ppm and $924 \mathrm{ppm}$ ) causes only a $9 \%$ and $13 \%$ reduction in the amount of $\mathrm{CO}_{2}$ required for extinction. Likewise, addition of $\mathrm{Fe}(\mathrm{CO})_{5}$ to the fuel stream at either $450 \mathrm{ppm}$ or $4500 \mathrm{ppm}$ causes only a $2 \%$ and $4 \%$ reduction in the amount of $\mathrm{CO}_{2}$ required. If we add $1 \% \mathrm{CH}_{4}$ to the air stream to move the flame location and hence the scalar dissipation rate, the reduction in the $\mathrm{CO}_{2}$ required for extinction with addition of $450 \mathrm{ppm}$ of $\mathrm{Fe}(\mathrm{CO})_{5}$ is slightly greater, but still only $11 \%$. These results are in contrast to those for $\mathrm{CF}_{3} \mathrm{Br}$ with $\mathrm{CO}_{2}$ in the cup burner which are shown at the bottom of the figure. There, we see that addition of $\mathrm{CF}_{3} \mathrm{Br}$ to either stream at mole fractions which would approximately halve the burning velocity leads to a reduction of the $\mathrm{CO}_{2}$ required for extinction by a factor of two to three. Clearly, $\mathrm{CF}_{3} \mathrm{Br}$ and $\mathrm{Fe}(\mathrm{CO})_{5}$ behave quite differently in the cup burner with respect to their ability to reduce the $\mathrm{CO}_{2}$ requirement for extinction.

Table 2 - Extinction volume fraction of $\mathrm{CO}_{2}$ in methane-air cup burner with and without various amounts of $\mathrm{Fe}(\mathrm{CO})_{5}$ or $\mathrm{CF}_{3} \mathrm{Br}$ added to the fuel or air stream (air flow $=41.6 \mathrm{l} / \mathrm{min}$ ).

\begin{tabular}{|c|c|c|c|}
\hline \multicolumn{2}{|r|}{ Catalytic Inhibitor } & $\begin{array}{c}\text { Vol \% } \mathrm{CO}_{2} \\
\text { at } \\
\text { Extinction }\end{array}$ & $\begin{array}{c}\% \text { Reduction } \\
\text { from } \\
\text { Pure } \mathrm{CO}_{2}\end{array}$ \\
\hline None & - & $15.7 \pm 0.6$ & - \\
\hline $\mathrm{Fe}(\mathrm{CO})_{5}$ & 450 ppm in Air & $14.1 \pm 0.6$ & $9.6 \pm 0.5$ \\
\hline “ & 924 ppm & $13.5 \pm 0.5$ & $13.5 \pm 0.8$ \\
\hline “ & $450 \mathrm{ppm}$ in Air w/ $1 \% \mathrm{CH}_{4}$ & $14.0 \pm 0.6$ & $10.7 \pm 0.6$ \\
\hline “ & 450 ppm in Fuel & $15.4 \pm 0.6$ & $1.3 \pm 0.1$ \\
\hline “ & 4500 ppm & $15.2 \pm 0.6$ & $2.6 \pm 0.2$ \\
\hline $\mathrm{CF}_{3} \mathrm{Br}$ & $1.3 \%$ In Air & $4.4 \pm 0.2$ & $72.0 \pm 4.1$ \\
\hline “ & $11 \%$ In Fuel & $8.7 \pm 0.3$ & $44.2 \pm 2.5$ \\
\hline
\end{tabular}

\subsubsection{Phosphorus Flames}

The question naturally arises as to whether the poor performance in the cup burner is specific to iron, or characteristic of super-effective inhibitors in general. To investigate this, we examined the cup-burner extinction data of TMP and DMMP from researchers at NMERI [60]. In their tests, they found that about $5 \%$ of DMMP was required for extinction, or $5.3 \%$ to $6.9 \%$ for TMP (all volume basis). It is surprising that so much is required to extinguish cup-burner flames considering that in methane-air flames, these phosphorus compounds have been shown to be 
about seventeen and three times more effective than $\mathrm{CF}_{3} \mathrm{Br}$ in premixed [61] and diffusion flames [62], respectively. In these tests in cup burners, on a molar basis, DMMP and TMP are less effective than $\mathrm{CF}_{3} \mathrm{Br}$, while on a mass basis, they are only about as effective as $\mathrm{CO}_{2}$. Further, at these concentrations, the agent could be working through oxygen starvation. For example, for DMMP and TMP which are combustible, the stoichiometric mole fraction in air is about $4.5 \%$ and $5.0 \%$. Hence, the actual mole fractions required for extinguishment are close to those at which the agent would consume all of the available oxygen in the air stream.

\subsubsection{Discussion}

We speculate that particle formation is the cause of the degraded performance of the metal agents. A visible outer annulus, apparently particles, was observed in all flames with added metals, and the blackbody radiation from that region increased with higher agent mole fraction. Finally, as discussed in refs. [9,42], the particle formation rates appear to be linked to their residence time in the cooler regions of the flame. Since the present cup-burner flames have quite different flow fields than either premixed or counterflow diffusion flames, it is likely that the condensation behavior in them is different. It is possible that metal compounds added to the air stream are sequestered as solid phase particles which are then convected away from the relevant radical recombination zones of the flame before they can affect the flame chemistry.

\subsubsection{Conclusions}

We have presented the first data on the extinction characteristics of the highly effective catalytic agent $\mathrm{Fe}(\mathrm{CO})_{5}$ added to a cup burner flame together with $\mathrm{CO}_{2}$. We have found that for this agent, its behavior in co-flow diffusion flames is drastically different from that in either premixed or counterflow diffusion flames. We postulate (but have not demonstrated) that the loss in effectiveness is due to condensation of the metal, metal oxides, or metal hydroxides. For methanol, the effect of the $\mathrm{Fe}(\mathrm{CO})_{5}$ on the fuel consumption rate (caused by the heat feedback to the liquid fuel surface) is small. For heptane, the effect is somewhat larger, and this is postulated to be due to reduced soot formation. In future research, it is suggested to study a wider variety of metal compounds to determine if this behavior is specific to $\mathrm{Fe}(\mathrm{CO})_{5}$ or generally true of super-effective metal compounds. Also, tests over a range of mole fractions of inhibitor would more help to determine if the indicated behavior is due to particle formation. It is of high importance to determine if phosphorus compounds, which have also been shown to be effective in premixed and counterflow diffusion flames, are effective at reducing the amount of $\mathrm{CO}_{2}$ required to extinguish a cup burner flame. It has been postulated that the reason for the lower effectiveness in these diffusion flames is particle formation and the subsequent sequestering of the active gas-phase inhibiting compounds prior to their introduction to the stabilization regions of the flame. Measurements of particles in these flames via traditional laser scattering and extinction would serve to determine if this is indeed the reason for loss of effectiveness. 


\section{Technical Problems}

This project uncovered numerous technical problems that were not anticipated at the outset of the work. While high mass fractions of the $\mathrm{Fe}(\mathrm{CO})_{5}$ could be added to zeolite and porous silica, some decomposition of the agent was indicated, especially for the zeolites, which were also pyrophoric on exposure to air. The most significant finding was that the super agents-even added alone-were not effective in flames more closely resembling fires (e.g., cup burner flames). This severely limits their utility, whether added alone, as absorbed material in a particle support matrix, or as a complexed compound.

\section{Recommendations}

We have clearly determined that $\mathrm{Fe}(\mathrm{CO})_{5}$ does not have the expected high efficiency at flame suppression when added, together with $\mathrm{CO}_{2}$, to the air stream of a cup burner flame of methane, heptane, or methanol, or to the fuel stream in a methane-air flame. We have not determined, however, the reasons for the poor performance. Tests with other potential super-effective agents in cup burner flames would determine if there was any utility of such compound in flames more closely resembling fires, and would show if this poor performance in cup burners was unique to $\mathrm{Fe}(\mathrm{CO})_{5}$ or a general property of the super-effective agents. Tests with the agents over a range of mole fraction in the air stream will help to determine the cause of the ineffectiveness. We have postulated that the reason for the lack of effectiveness of $\mathrm{Fe}(\mathrm{CO})_{5}$ in the cup burner flames is condensation of the active species to particles of iron, iron oxide, or iron hydroxide, caused by the particular time-temperature history of the cup burner flames. We recommend testing this hypothesis by performing classical laser scattering and extinction tests in cup-burner flames with added $\mathrm{CO}_{2}$ and super agents to determine the particle formation properties of the chemical systems.

Our evaluations of the data of other researchers concerning the performance of the phosphorus compounds DMMP and TMP added alone in cup burner flames showed them to be fairly ineffective. This too is surprising considering their strong inhibition of premixed and counterflow diffusion flames. We recommend that tests be performed with blends of TMP or DMMP with $\mathrm{CO}_{2}$ added to the air stream of cup burner flames to determine if they too suffer from the loss of effectiveness experienced by $\mathrm{Fe}(\mathrm{CO})_{5}$. Finally, since the cup burner is a widely used flame for assessment of suppressant effectiveness, we recommend experiments and numerical modeling to more fully understand the chemical and flow-field effects which lead to flame extinction in these flames for a range of inhibitor types.

\section{Conclusions}

We have shown that an iron pentacarbonyl mass fraction of $0.33,0.26,0.21$, and 0.14 to 2.0 can be absorbed into zeolite-NaX, zeolite-NaY, porous silica, and aerogel, respectively. However, we have also shown that $\mathrm{Fe}(\mathrm{CO})_{5}$ added to zeolites is pyrophoric and decomposes on exposure to air. Because of the sensitivity of aerogel particles to moisture, our experiments found it a very 
difficult to work with. Finally, experiments with $\mathrm{I}_{2}$-impregnated silica gel, while perhaps delivering as much as $1.2 \%$ of $\mathrm{I}_{2}$ (by mass) to the flame, failed to show significant flame speed reduction. Further, based on literature values of the amount of $\mathrm{I}_{2}$ required for flame inhibition, an $\mathrm{I}_{2}$ mass fraction of $0.88 \%$ would be required an $10 \%$ reduction in flame speed. To achieve this $\mathrm{I}_{2}$ loading, the inert carrier would have to be present at about $4.5 \%$. Extinction mass loadings would be about nine times this, or about $40 \%$ by mass of the inert carrier. Obviously, for such conditions, the advantage of the chemically active agent becomes marginal.

We have shown that the powerful flame inhibition properties of iron is not unique to $\mathrm{Fe}(\mathrm{CO})_{5}$, but is about the same for ferrocene-a much less toxic form of iron. We have shown that combining ferrocene with $\mathrm{CO}_{2}$ mitigates the loss of effectiveness in premixed flames, but that mixing ferrocene with HFC's is nor particularly effective due to the formation of stable $\mathrm{Fe}_{\mathrm{x}} \mathrm{F}_{\mathrm{y}}$ compounds (especially $\mathrm{FeF}$ and $\mathrm{FeF}_{2}$ ).

The agent $\mathrm{Fe}(\mathrm{CO})_{5}$, alone or combined with $\mathrm{CO}_{2}$, is not effective in cup burner flames. We speculate that the reason for the lack of effectiveness is the loss of active inhibiting species to condensed phase particles. Hence, we do not believe that this agent, combined with any support matrix, would be particularly effective either.

Acknowledgements: We thank Prof. Dino Megarides of UIC for helpful discussions, and for sending us his ferrocene evaporator, which we studied in designing our own. The assistance of Anthony Lazzarini and Pasan Wanigarathne in conducting many of the experiments is gratefully acknowledged. The essential contributions of Valeri Babushok, Don Burgess, Michael, Zachariah, and Wing Tsang are gratefully acknowledged. This research is part of the Department of Defense's Next Generation Fire Suppression Technology Program, funded by the DoD Strategic Environmental Research and Development Program under contract number W74RDV83528667. Internal NIST funding is also gratefully acknowledged.

\section{References}

[1]. Glassman, I., Combustion, A cedemic Press, New York, NY, 1977.

[2]. Lask, G. and Wagner, H.G., Proceeding of the Combustion Institute, Vol. 8, Williams and Wilkins Co., Baltimore, 1962, pp. 432-438.

[3]. Jost, W., Bonne, U., and Wagner, H.G., Chem. Eng. N ews 39:76 (1961).

[4]. Bonne, U., Jost, W., and Wagner, H.G., Fire Res. A bstracts Rev. 4:6 (1962).

[5]. Rumminger, M.D., Reinelt, D., Babushok, V., and Linteris, G.T., Combust. Flame 116:207 (1999).

[6]. Reinelt, D. and Linteris, G.T., Proceedings of the Combustion Institute, Vol. 26, The Combustion Institute, Pittsburgh, PA, 1996, pp. 1421-1428.

[7]. Rumminger, M.D. and Linteris, G.T., Halon Options Technical Working Conference, Albuquerque, N M, 1999, pp. 511-521.

[8]. Linteris, G.T., Rumminger, M.D., and Babushok, V.I., Combust. Flame 122:58 (2000). 
[9]. Rumminger, M.D. and Linteris, G.T., Combust. Flame 123:82 (2000).

[10]. Rumminger, M.D. and Linteris, G.T., Combust. Flame 120:451 (2000).

[11]. Rumminger, M.D. and Linteris, G.T., Fire Safety Science: Proceedings of the Sixth International Symposium, International Association for Fire Safety Science, Marne-LaVallee, France, 2000, pp. 289-300.

[12]. Taylor, B. N. and Kuyatt, C. E., Guidelines for Evaluating and Expressing the U ncertainty of NIST M easurement Results, National Institute of Standards and Technology, NIST Technical Note 1297, 1994.

[13]. Moffat, R.J., Transactions of the A SM E 104:250 (1982).

[14]. Breck, D.W., in M olecular Sieves (Meier, W. M. and Uytterhoeven, J. B., Ed.), American Chemical Society, Washington, D.C., 1973.

[15]. Peters, N., Combust. Sci. Technol. 30:1 (1983).

[16]. Reed, M.D., Williams, B.A., Sheinson, R.S., and Fleming, J.W., Eastern States Section $M$ eeting of The Combustion Institute, 83-86.

[17]. Trees, D. and Seshadri, K., Combust. Sci. Technol. 122:215 (1997).

[18]. Andrews, G.E. and Bradley, D., Combust. Flame 18:133 (1972).

[19]. Chelliah, H.K., Yu, G., Hahn, T.O., and Law, C.K., Proceeding of the Combustion Institute, V ol. 24, The Combustion Institute, Pittsburgh, 1993, pp. 1083-1090.

[20]. Lask, G. and Wagner, H.G., Proceedings of the Combustion Institute, Vol. 8, Williams and Wilkins Co., Baltimore, 1962, pp. 432-438.

[21]. Howard, J.B. and Kausch, W.J., Prog. Energy Combust. Sci. 6:263 (1980).

[22]. Zhang, J. and Megaridis, C.M., Proceedings of the Combustion Institute 25:593 (1994).

[23]. Zhang, J. and Megaridis, C.M., Combust. Flame 105:528 (1996).

[24]. Carty, P., Grant, J., and Metcalfe, E., A ppl. O rganomet. Chem. 10:101 (1996).

[25]. Kasper, M. and Siegmann, K., Combust. Sci. Technol. 140:333 (1998).

[26]. Kasper, M., Sattler, K., Siegmann, K., Matter, U., and Siegmann, H.C., J. A erosol Sci. 30:217 (1999).

[27]. Kishore, K., Kannan, P., and Iyanar, K., J. Polym. Sci., Part A: Polym. Chem. 29:1039 (1991).

[28]. Linteris, G.T., Rumminger, M.D., Babushok, V.I., and Tsang, W., Proceedings of the Combustion Institute, Vol. 28, The Combustion Institute, Pittsburgh, PA, 2000, pp. (accepted).

[29]. Babushok, V. and Tsang, W., "Inhibitor Rankings for Hydrocarbon Combustion", submitted, Combust. Flame, 2000.

[30]. Linteris, G.T. and Truett, L., Combust. Flame 105:15 (1996).

[31]. Pelino, M., Tomassetti, M., Piacente, V., and D'Ascenzo, G., Thermochim. Acta 44:89 (1981).

[32]. Kee, R. J., Grcar, J. F., Smooke, M. D., and Miller, J. A., A Fortran Computer Program for M odeling Steady Laminar O nedimensional Premixed Flames, Sandia National Laboratories Report, SAND85-8240, 1991.

[33]. Kee, R. J., Rupley, F. M., and Miller, J. A., CHEM KIN -II: A Fortran Chemical Kinetics Package for the Analysis of Gas Phase Chemical Kinetics, Sandia National Laboratory, SAND89-8009B, 1989.

[34]. Kee, R. J., Dixon-Lewis, G., Warnatz, J., Coltrin, R. E., and Miller, J. A., A Fortran Computer Package for the Evaluation of Gas-Phase, Multicomponent Transport Properties, Sandia National Laboratory, SAN D86-8246, 1986.

[35]. Lewis, K.E. and Smith, G.P., J. A m. Chem. Soc. 106:4650 (1984). 
[36]. Turnbull, A.G., A ust. J. Chem. 20:2059 (1967).

[37]. Sabbah, R. and Perez, J.A.G., Thermochemica A cta 297:17 (1997).

[38]. Reid, R. C., Prausnitz, Y. M., and Sherwood, T. K., The Properties of Gases and Liquids, McGraw-Hill, New York, 1987.

[39]. Wang, H. and Frenklach, M., Combust. Flame 96:163 (1994).

[40]. Sung, C.J., Li, B., Law, C.K., and Wang, H., Proceedings of the Combustion Institute 27:1523 (1998).

[41]. Rumminger, M. D. and Linteris, G. T., Inhibition of Premixed Carbon M onoxide-H ydrogenOxygen-N itrogen Flames by Iron Pentacarbonyl, National Institute of Standards and Technology, NIST IR 6360, 1999.

[42]. Rumminger, M.D. and Linteris, G.T., Combust. Flame 2001).

[43]. Linteris, G.T., Burgess, D.R., Babushok, V., Zachariah, M., Tsang, W., and Westmoreland, P., Combust. Flame 113:164 (1998).

[44]. Tsang, W., Personal Communication, April 1999.

[45]. Burgess, D.R., Zachariah, M.R., Tsang, W., and Westmoreland, P.R., Prog. Energy Combust. Sci. 21:453 (1995).

[46]. Gurvich, L. V., Iorish, V. S., Chekhovskoi, D. V., Ivanisov, A. D., Proskurnev, A. Yu., Yungman, V. S., Medvedev, V. A., Veits, I. V., and Bergman, G. A., IVTH A NTHERM 0 Database on Thermodynamic Properties of Individual Substances, Institute of High Temperatures, Moscow, 1993.

[47]. Hynes, R.G., Mackie, J.C., and Masri, A.R., Combust. Flame 113:554 (1998).

[48]. Fristrom, R.M . and Sawyer, R.F., A GARD Conference on Aircraft Fuels, Lubricants, and Fire Safety, A GARD-CP 84-71, 1971, pp.

[49]. Linteris, G.T., Rumminger, M.D., and Babushok, V., Halon O ptions Technical W orking Conference, Albuquerque, N M, 2000, pp. 129-140.

[50]. Rosser, W. A, Inami, S. H., and Wise, H., Study of the M echanisms of Fire Extinguishment of Liquid Rocket Propellants, WADC Technical Report 59-206, 1959.

[51]. Rosser, W.A., Inami, S.H., and Wise, H., Combust. Flame 7:107 (1963).

[52]. Hastie, J. W., H igh Temperature V apors, A cademic Press, N ew York, 1975.

[53]. Lott, J.L., Christian, S.D., Sliepcevich, C.M., and Tucker, E.E., Fire Technol. 32:260 (1996).

[54]. Noto, T., Babushok, V., Hamins, A., and Tsang, W., Combust. Flame 112:147 (1998).

[55]. Fallis, S., Reed, R., Lu, Y.-C., Wierenga, P.H., and Holland, G.F., H al on O ptions Technical W orking Conference, Albuquerque, NM, 2000, pp. 361-370.

[56]. Hamins, A., Trees, D., Seshadri, K., and Chelliah, H.K., Combust. Flame 99:221 (1994).

[57]. Hirst, B. and Booth, K., FireT echnol. 13:296 (1977).

[58]. Linteris, G.T. and Gmurczyk, GW., in Fire Suppression System Performance of A Iternative Agents in Aircraft Engine and Dry Bay Laboratory Simulations (R.G. Gann, Ed.), National Institute of Standards and Technology, Gaithersburg, MD, 1995.

[59]. Gilbert, A.G. and Sulzmann, K.G.P., J. Electrochem. Soc. 121:832 (1974).

[60]. Tapscott, R. E., Mather, J. D., Heinonen, E. W., Lifke, J. L., and Moore, T. A., Identification and Proof Testing of N ew Total Flooding A gents: Combustion Suppression Chemistry and CupBurner Testing, New Mexico Engineering Research Institute, N MERI 97/ 6/ 33010, 1998.

[61]. Korobeinichev, O., Mamaev, A., Sokolov, V., Bolshova, T., Shvartsberg, V., Zakharov, L., and Kudravtsev, I., H alon O ptions Technical W orking Conference, Albuquerque, NM, 2000, pp. 164-172.

[62]. Macdonald, M.A., Jayaweera, T.M., Fisher, E.M., and Gouldin, F.C., Combust. Flame 116:166 (1999). 